\title{
Effect of Infill Walls on the Drift Behavior of Reinforced Concrete Frames Subjected to Lateral-Load Reversals
}

\author{
CEMALETTIN DÖNMEZ and M. ALPER ÇANKAYA
}

Civil Engineering Department, Izmir Institute of Technology, Izmir, Turkey

\begin{abstract}
Four-story, single-bay, 1/5 scaled reinforced concrete frames were tested with and without infill walls. Frames were subjected to pseudo-static cyclic loading. In addition, impact hammer measurements were made to obtain the natural frequencies and modal shapes at certain drift levels. It was observed that infill walls cause major changes on both the stiffness and the drift behavior of the frames. Effect of observed changes can be either advantageous or disadvantageous depending on failure mode. Results showed that the distribution of drift that is based on the mode shapes has higher local concentrations than the distribution observed under forced static conditions.
\end{abstract}

Keywords Infill; Walls; Cyclic Load; Reinforced Concrete; Inter-Story Drift Ratio; Mode Shapes; Natural Frequencies

\section{Introduction}

Clay brick infill walls are commonly used as partitions in reinforced concrete (RC) structures. It is not an easy task to incorporate the effect of infill walls into the structural design because of the variation in the material properties and the highly nonlinear behavior. The current design practice typically ignores the possible effects of infill walls on the structural behavior. Under gravity, infill walls can have a positive effect on the behavior by providing alternative load paths. The situation is quite different under seismic loading. Based on earlier studies [Fiorato et al., 1970; Mehrabi et al., 1996; Negro and Verzeletti, 1996; Negro et al., 1996; Applied Technology Council, 1999; Dolsek and Fajfar, 2001; Zarnic et al., 2001; Erdem et al., 2006; Hashemi and Mossalam, 2006; Pinto and Taucer, 2006; Dolsek and Fajfar, 2008; Pujol and Fick, 2010; Cankaya, 2011], it is well known that infill walls change the strength, stiffness and deformation properties of the frame structures. Typically, the strength and stiffness of the frames increase and the average drifts decrease compared to those of the bare frames. A frame-infill wall system typically reaches its peak strength at low interstory drifts of $0.3-1.0 \%$. These peak values are generally not sustainable, and the frames usually fail at interstory drifts of 1.0-2.5\% [Fiorato et al., 1970; Mehrabi et al., 1996; Negro and Verzeletti, 1996; Dolsek and Fajfar, 2001; Zarnic et al., 2001; Pujol and Fick, 2010]. The main body of literature on frames with infill walls concentrates on identifying and setting rules about the behavior of infill walls at the story levels. There are several possible failure modes [Fiorato et al., 1970; Mehrabi et al., 1996; Applied Technology Council, 1999]. The dominant failure in infill walls may take place in the form of horizontal

Received 10 August 2011; accepted 17 January 2013.

Address correspondence to Cemalettin Dönmez, Izmir Institute of Technology, Civil Engineering Department, Gulbahce, 35430 Urla-Izmir, Turkey. E-mail: cemalettindonmez@iyte.edu.tr 
shear cracking, diagonal cracking or corner crushing. The nature of failure depends on the relation of the strength and the stiffness of frame to that of the infill wall. Based on these relations, frame members may also fail by tension in the columns or by shear and/or flexure in the beams or columns. The infill may cause local crushing in the frame members by the concentration of loads into the local regions.

Studies at the story level are the basis for studying behavior at the structural level. The global response of the multi-story structures are typically studied by computer simulations based on the local data [Madan et al., 1997; Dolsek and Fajfar, 2002; Smyrou et al., 2008; Rodrigues et al., 2008; Gerardo et al., 2011]. There is a limited set of experimental studies that have multi-story specimens to investigate the effect of local behavior on the global response of the system [Fiorato et al., 1970; Negro and Verzeletti, 1996; Dolsek and Fajfar, 2001; Pinto and Taucer, 2006; Pujol and Fick, 2010].

Existing studies on multi-story frames with infill walls revealed that the drift capacity is controlled by the failure mode of the system. Weak perimeter frames typically resulted in the premature failure of the system. The presence of regular infill panels prevent the energy dissipation to take place in the frame even if considerable damage took place in the panels [Negro and Verzeletti, 1996]. As long as the demands are within the capacity of the frame-infill systems, deformations are much smaller under seismic loads compared to those of bare frame systems. Forcing the system beyond its capacities causes the loss of heavily loaded infill walls at lower stories and induces the formation of a soft story, causing detrimental effects [Pinto and Taucer, 2006]. There is evidence [Dolsek and Fajfar, 2001; Lee and Woo, 2001; Pujol and Fick, 2010] that if the drift capacity of the frame-infill system is equal to or more than the seismic demands, the infill walls are beneficial. On the other hand, irregularities in the infill panels could result in unacceptably large deformations in the frames at early stages [Negro and Verzeletti, 1996].

The out-of-plane behavior of infill walls bounded by a frame has also been extensively studied [Angel et al., 1994; Shapiro et al., 1994; Calvi and Bolognini, 2001]. The outof-plane strength depends on the compressive strength of the masonry and resistance is generated through arching. Shapiro et al. [1994] suggested that if the aspect ratio of the infill wall is less than or equal to $1 / 10$ (thickness/height), then the infill wall is safe against an out-of-plane failure up to horizontal acceleration levels twice that of acceleration of gravity. Calvi and Bolognini [2001] demonstrated that the out-of-plane resistance of infill panels could be increased dramatically by embedding modest amounts of reinforcement in the mortar that is placed on the faces of the infill panels. The study presented here is based on the assumption that necessary measures are taken to prevent the out-of-plane failure of infill walls.

Even though existing studies answer the question of whether infill walls are beneficial under seismic demands, the definition of the main parameter, the drift capacity, that is used to rate the satisfactory behavior is not clear. What is the sufficient drift capacity? Which drift should be considered: the drift at the floor level or the average drift in the structure? What parameters control the drift profile and its history throughout the loading? Could the drift be manipulated for improving seismic resistance? The purpose of the study presented in this paper is to investigate the in-plane drift behavior of multistory RC frames with infill walls to provide hard data and address some of the questions about the drift capacity and its distribution along the height of the frames. Four-story scaled RC frames were tested with and without infill walls. The frames were subjected to pseudo-static cyclic loading with a triangular profile. Considering that natural frequencies and modal shapes are interrelated with the stiffness and drift behavior under dynamic loading, these parameters are also investigated. The dynamic parameters are estimated through modal analysis methods by using impact data obtained from frames after each loading cycle. 
The testing program and specimens are presented in the next section, followed by the test setup and the results of the pseudo-static and impact hammer tests. The results of the tests are then discussed, followed by proposals about future work and conclusions of the study.

\section{Testing Program and Specimens}

Four-story, one-bay, scaled RC frames were tested. Frames were not models of any prototype structure. By similitude laws, there are three independent units related to the observations considered: (1) length, (2) acceleration, and (3) force. The test structure was proportioned to have a length scale of $1 / 5$ for practical reasons. To attain the acceleration of gravity and Young's modulus of elasticity in the test structure similar to those of a prototype structure, the time and the force were scaled by factors of $1 / \sqrt{5}$ and $1 / 25$, respectively. The selected scale factors enabled the model structure to attain "elastic" stress-strain levels similar to those observed in a prototype structure. A further study performed on the effect of scaling on the capacities of the frames in the nonlinear range reveal that the conclusions derived from test structure are applicable to the prototype structure. Details of this study are presented in Appendix A.

The main parameters of the study were the reinforcement details of the frames and the presence of the infill walls. Two types of reinforcement detailing were chosen. These are the typical seismically insufficient detailing used in Turkish practice (brittle detailing) and the ductile reinforcement detailing set forth in the Turkish Earthquake Code [2007] (ductile detailing). Insufficient details were given by longitudinal reinforcement splice lengths, stirrup locations, intervals, and hook geometry. Infill walls were built with hollow clay tiles filling the full span at every story. A total of four frames were constructed based on the defined parameters. Frames \#1 and \#2 were bare frames with brittle and ductile detailing, respectively, and Frames \#3 and \#4 had infill walls with brittle and ductile detailing, respectively. The strong-column weak-beam requirement was not satisfied in any of the frames.

The overall geometry, dimensions and reinforcement details of the test frames are presented in Fig. 1. Dimensions of the girders presented in the figure were valid for Frames \#2 to \#4 which were modified to enable convenient casting of concrete. The dimensions of Frame \#1 were $50 \times 90 \mathrm{~mm}^{2}$ for the girder web and $400 \times 30 \mathrm{~mm}^{2}$ for the slab. The slabs were designed such that additional masses could be attached on the system. The test results of the deformed bars revealed that they were class S420 (minimum $420 \mathrm{MPa}$ yield strength with a measured average of $480 \mathrm{MPa}$ ) according to the Turkish RC code [2000]. The stirrups were bent from $5 \mathrm{~mm}$ cold-drawn plain bars. Tests on these bars showed that they had an average yield strength of $420 \mathrm{MPa}$, but had two classes of maximum strain capacity, $3 \%$ and $10 \%$. Hollow clay tiles of $57 \times 100 \times 130 \mathrm{~mm}^{3}$ were cut from $130 \times 185 \times 280 \mathrm{~mm}^{3}$ commercial tiles. The cut out pieces had about a $50 \%$ solid ratio in cross section. The compressive strength based on the gross section of the clay tiles was measured to be $9.5 \mathrm{MPa}$ along the voids and $2 \mathrm{MPa}$ perpendicular to the voids. The proportion of the mortar used in the infill walls was 4:1:1 (sand: lime: cement). The mortar of the of Frame \#3 was carried out as planned, but that of Frame \#4 had a richer mix in cement due to workmanship. Based on diagonal compression tests, the average shear strengths of the infill walls were $0.33 \mathrm{MPa}$ and $0.83 \mathrm{MPa}$ for Frames \#3 and \#4, respectively. The effects of such a difference in the mortar strength manifested itself in the results of the infilled frames. The concrete was cast with the frames set upright. It was intended to have a concrete compressive strength of approximately $20 \mathrm{MPa}$. Because of the retarding effect of the plasticizer and the old age of 

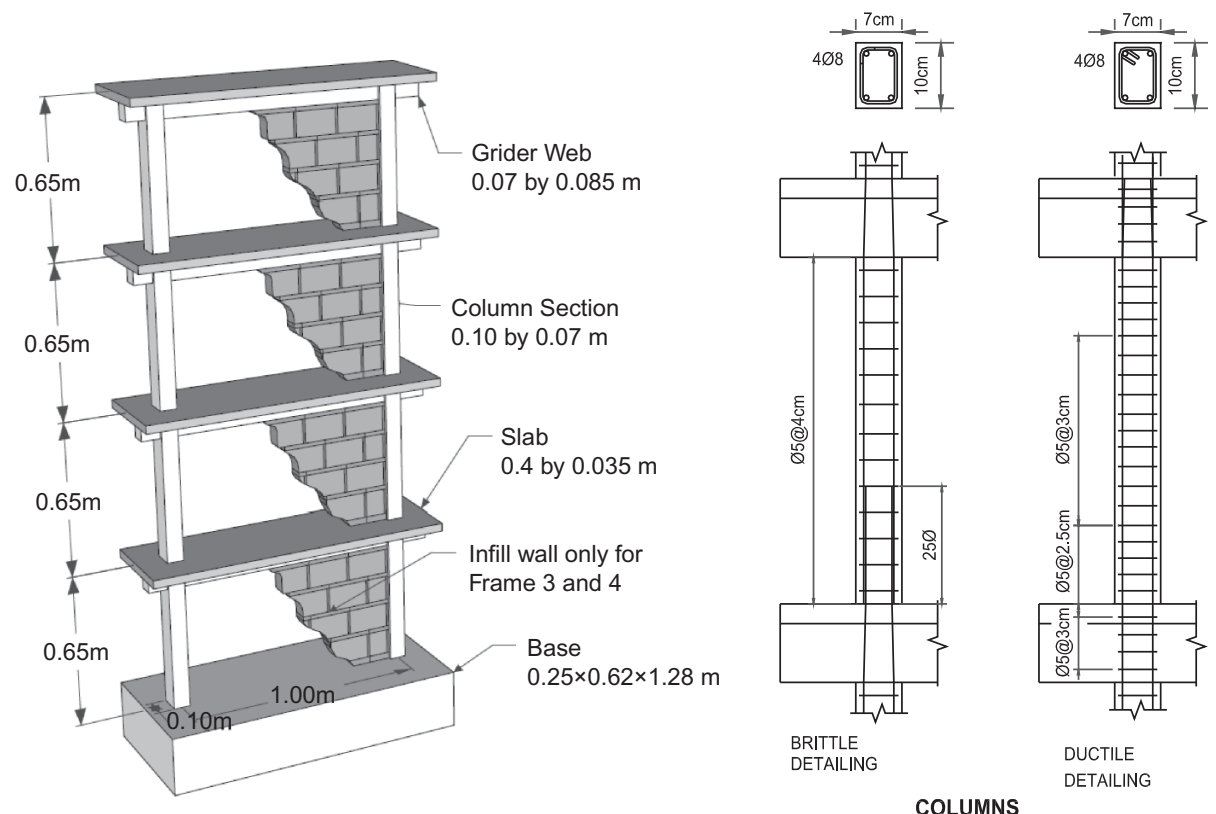

COLUMNS
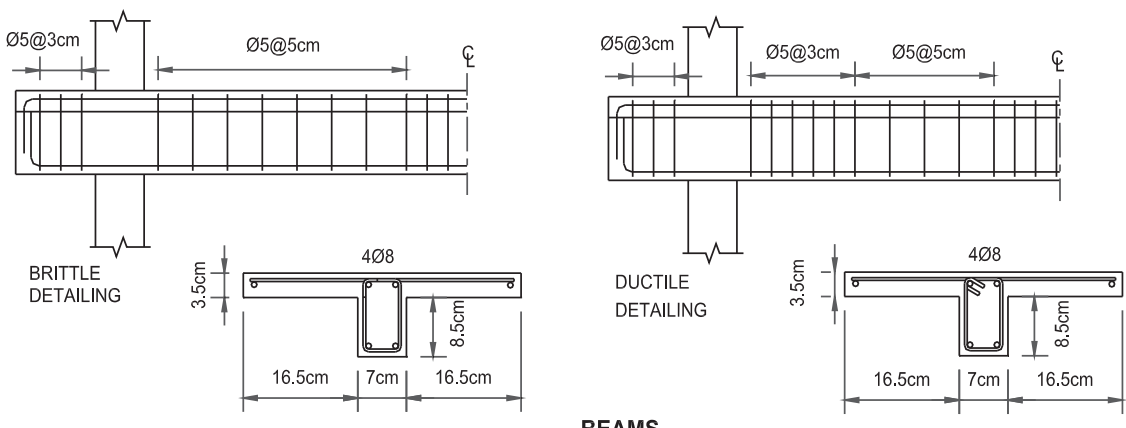

BEAMS

FIGURE 1 The dimensions and the reinforcement details of the tested frames.

the concrete at the time of testing measured concrete cylinder strengths of the frames were 41, 36, 36, and $25 \mathrm{MPa}$ for Frames \#1 to \#4, respectively, on the day of the experiments. Because of the higher strengths of the concrete, axial load levels with respect to the capacity became lower than expected. Higher strengths of concrete also caused higher shear and bond strengths that prevented the effects of reinforcement deficiencies such as insufficient splice length and inefficiency of $90^{\circ}$ stirrup hooks.

The axial loads of the frames were provided by additional masses at the floor levels to satisfy the static/dynamic dual purpose of the specimens. The additional weights were selected to ensure that the uncracked natural periods of the model frames and the prototype structure were similar. For typical RC moment frame structures, the periods can be expected to be in the neighborhood of N/10 for bare frames and N/20 for frames with infill walls, where $\mathrm{N}$ is the number of stories. Hence, the corresponding periods of a prototype frame can be expected to be $0.4 \mathrm{~s}$ for bare frames and $0.2 \mathrm{~s}$ for infill frames. Similitude requirements with the selected scaling factors of independent units dictate that the period of a prototype structure should be $\sqrt{5}$ times the period of the test structure. As presented in Table 1, the measured uncracked periods of the model frames without infill walls satisfied 
TABLE 1 The measured first natural periods of the test frames and the corresponding values for the prototype frames

\begin{tabular}{lcc}
\hline & $\begin{array}{c}\text { The measured uncracked } \\
\text { periods in the test }(\mathrm{s})\end{array}$ & $\begin{array}{c}\text { Values converted to the scale of a } \\
\text { prototype structure }\left(P_{m}^{*} \sqrt{5}\right)(\mathrm{s})\end{array}$ \\
\hline Frame 1 & 0.20 & 0.44 \\
Frame 2 & 0.18 & 0.40 \\
Frame 3 & 0.060 & 0.13 \\
Frame 4 & 0.063 & 0.14 \\
\hline
\end{tabular}

the target periods of the prototype frames satisfactorily. The periods of the frames with infill walls were on the higher side. It was also intended to achieve a stress level higher than $10 \%$ of the column capacity under gravity loads in the $1^{\text {st }}$ story columns by additional masses. However, because of the limited space for additional masses and unexpectedly high concrete strengths, the $10 \%$ axial load level for columns under gravity loads was not satisfied.

\section{Test Setup}

The test setup was developed to suit both the static and dynamic experiments. As a result, a detachable in-plane loading system was designed and constructed. Because of the additional masses $(\sim 1600 \mathrm{~kg})$ attached to the floor beams, a backup frame was also designed and constructed. The out-of-plane stability of the frames was provided by an external steel frame supported by the backup frame. The static loading program included in-plane pseudo-static loading with an increasing intensity. Static loading was applied through a vertical beam system designed to apply an inverse triangular load distribution to the frames, as shown in Fig. 2. The loads applied to the system were measured by four load cells positioned at the floor levels. The displacements at each level were measured by displacement transducers. The strains at the plastic end regions of the $1^{\text {st }}$ story columns were monitored by four strain gauges at the longitudinal reinforcing bars. The rigid body motion of the base block was also monitored using three displacement transducers. The loading levels were set by targeted interstory drifts of the first floor. After each loading cycle, the lateral loading was stopped and the loading system was detached to prepare the system for impact hammer tests. The natural frequencies and the modal shapes of the frames were estimated by modal analysis of the recorded vibration data.

\section{Pseudo-Static Tests}

The interstory drift ratios applied in the first story are summarized in Table 2. Considering that the frames with infill walls were to be subjected to major strength and stiffness degradations at lower drift levels, drifts in the first two cycle groups of Frames \#3 and \#4 were kept at lower levels. Two full cycles of load were applied at every drift level.

The tested bare frames showed similar behavior up to interstory drift levels of $2 \%$ in the $1^{\text {st }}$ story. In both frames, bending cracks were formed on the tension sides of the $1^{\text {st }}$ story columns in the first two cycles. Similar bending cracks kept forming in the upper story columns with increasing drifts. A diagonal crack was initiated in one of the $1^{\text {st }}$ story beamcolumn joint in the second cycle. Some of the bending cracks developed into bending-shear cracks at a first-story drift ratio of $1.1 \%$. At this drift level, new diagonal cracks formed at 


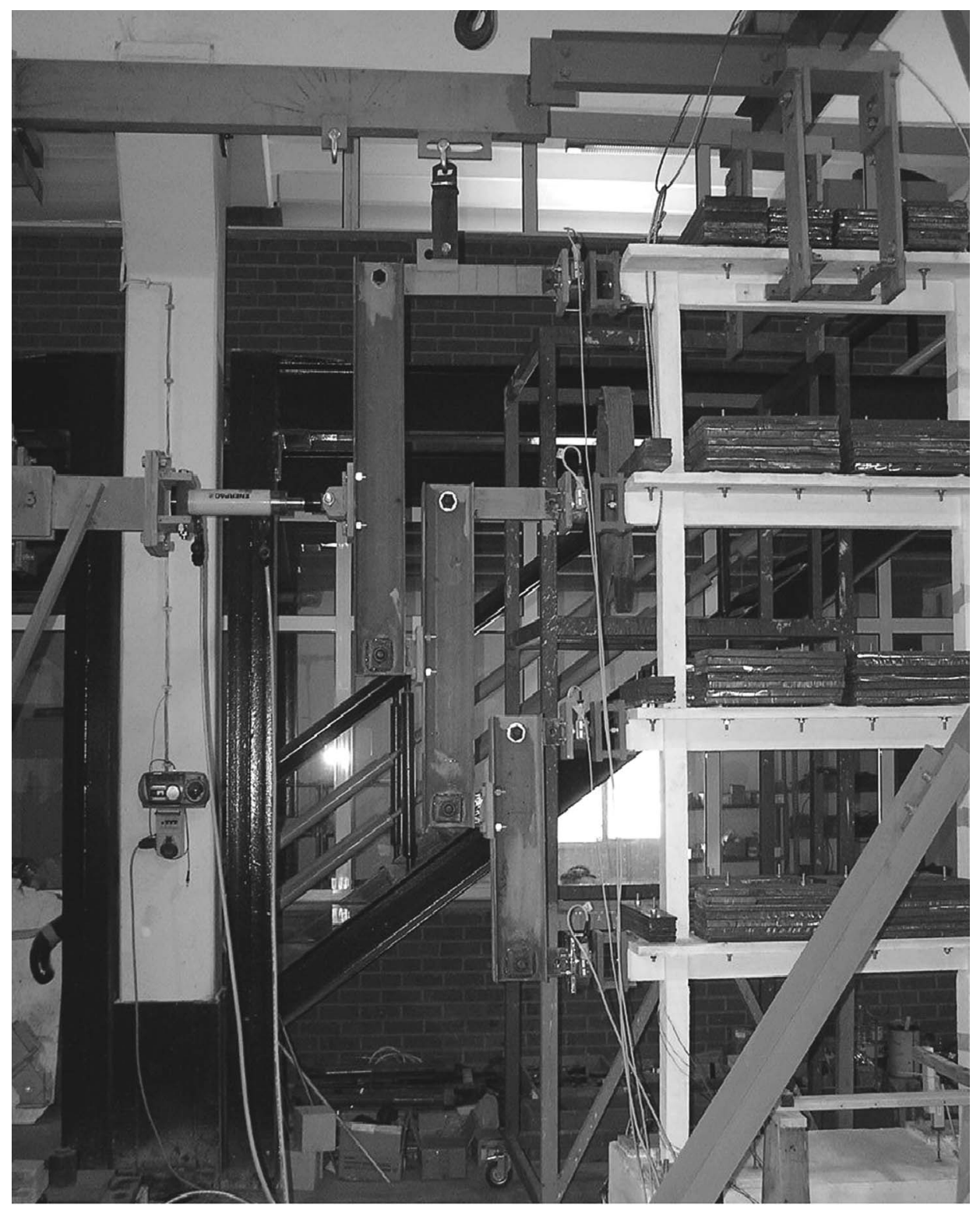

FIGURE 2 The test setup.

TABLE 2 The applied interstory drift ratios (\%) at the $1^{\text {st }}$ story (each cycle is applied twice)

\begin{tabular}{lcccccc}
\hline & Cycle 1 & Cycle 2 & Cycle 3 & Cycle 4 & Cycle 5 & Cycle 6 \\
\hline Frame \#1 & 0.7 & 1.1 & 1.5 & 1.9 & - & - \\
Frame \#2 & 0.7 & 1.1 & 1.5 & 2.1 & 2.5 & 3.4 \\
Frame \#3 & 0.1 & 0.3 & 0.7 & 1.0 & 1.4 & 1.8 \\
Frame \#4 & 0.1 & 0.3 & 0.6 & 0.9 & 1.5 & 2.0 \\
\hline
\end{tabular}



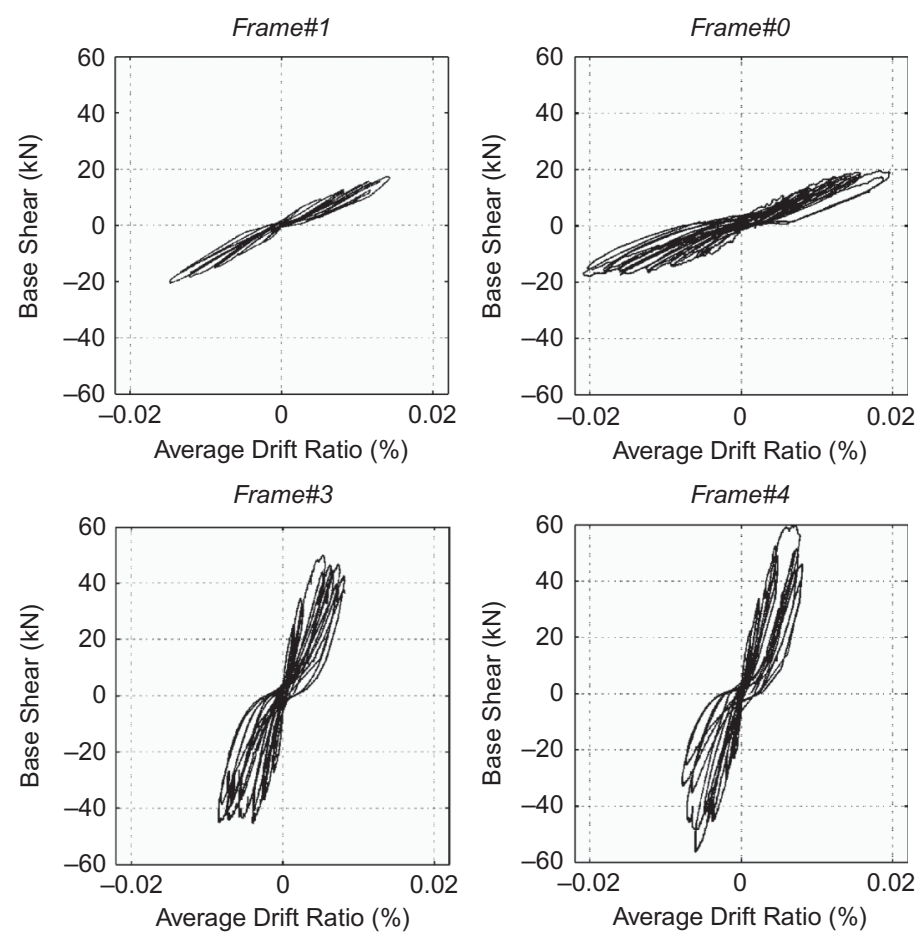

FIGURE 3 The average drift ratio versus the total base shear relations of the frames.

the other beam-column joints of the $1^{\text {st }}$ and the $2^{\text {nd }}$ story. Figure 3 presents the base shear vs. the average drift relation for all of the test frames. As shown in Fig. 3, Frames \#1 and \#2 reached maximum lateral load capacities of $20.3 \mathrm{kN}$ and $19.7 \mathrm{kN}$, respectively. The performed limit analysis indicated that both of the bare frames should reach their limits by the formation of plastic hinges at both ends of the $1^{\text {st }}$ story columns. Calculated capacities were $21.0 \mathrm{kN}$ and $19.8 \mathrm{kN}$ for Frames \#1 and \#2, respectively. Considering the proximity of the strength values and the observed crack pattern, the limit analysis is satisfactory in calculating the capacity of the bare frames. Further details about the limit analysis are presented in Appendix B.

Material tests and observations during the experiments indicated that the infill wall of Frame \#4 had a higher strength than that of Frame \#3. This unintentional parameter changed the failure mode of Frame \#4. At peak strength, the lateral load level of Frames \#3 and \#4 reached to $49.5 \mathrm{kN}$ and $59.6 \mathrm{kN}$, respectively (Fig. 3). Frame \#3 reached its capacity by the formation of plastic hinges at both ends of first story columns (Fig. 4). On the other hand, Frame \#4 reached its capacity by the formation of diagonal crack zones at the top ends of both columns at the $1^{\text {st }}$ story. These cracks were formed in the column under tension, and the cracks in the opposite columns were almost perpendicular to each other (Fig. 5). Tests of the frames with infill walls stopped at similar drift levels, even though Frame \#4 had better reinforcement detailing. Test of Frame \#3 was stopped based on the security concerns related to the possibility of a brittle failure. By the end of the test, the $1^{\text {st }}$ and $2^{\text {nd }}$ stories of Frame \#3 had widespread damage in both the infill walls and the frame members (Fig. 4). Test of Frame \#4 was stopped due to heavy damage concentrated in the columns of the $1^{\text {st }}$ story (Fig. 5). Infill of the $1^{\text {st }}$ story maintained its global integrity up to the last two cycles with relatively minor damage. In the last two cycles, crushing took 


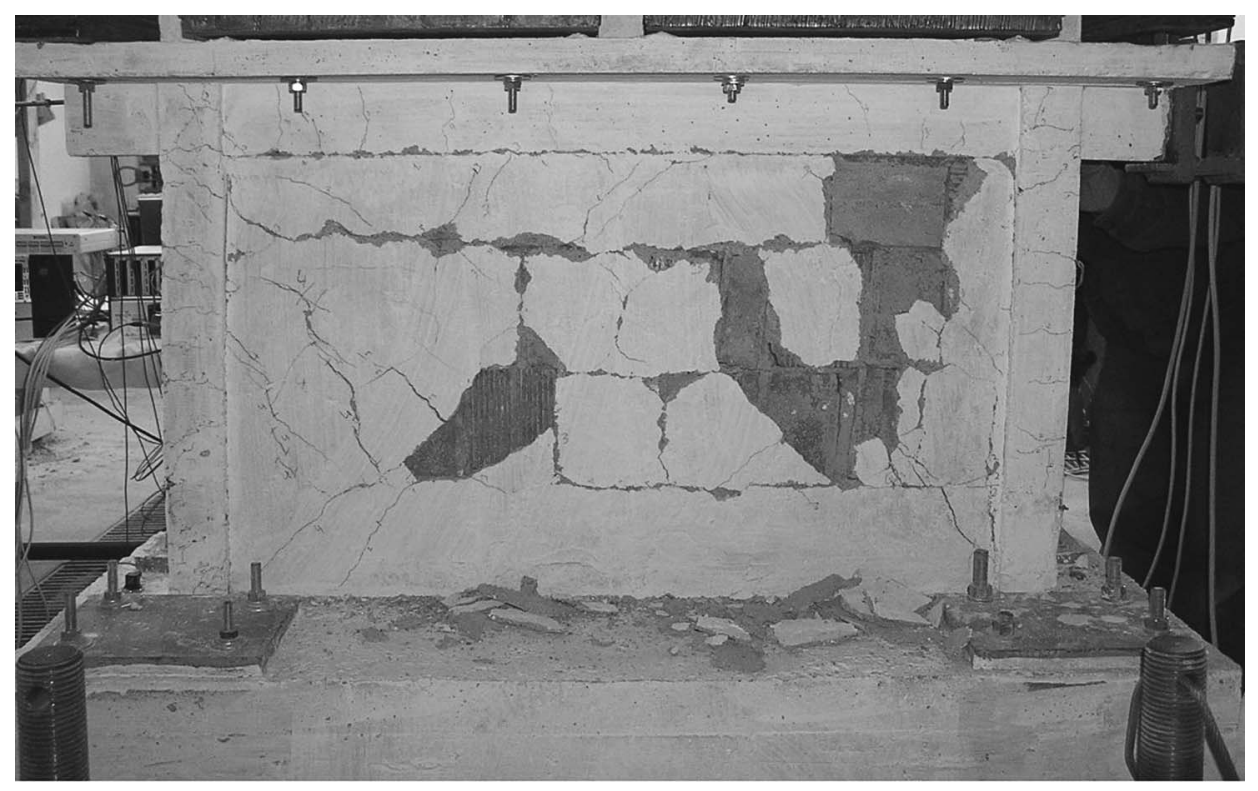

FIGURE 4 The damage in the $1^{\text {st }}$ story of Frame $\# 3$ after the $5^{\text {th }}$ loading group.

place at the top corners. No damage was observed in the infill walls of the upper floors except separation cracks at the frame infill wall interfaces.

The cumulative energy dissipation of the tested bare frames is presented in Fig. 6a. The difference in the reinforcement detailing was evident both in the magnitude and the sustainability of the energy dissipated under repeated cycles at the same drift levels. Frame \#2 had a higher and sustained energy dissipation compared to Frame \#1. Similarly, cumulative energy dissipated in the frames with infill walls is presented in Fig. 6b. Frame \#3 presented a stable energy dissipation that kept its rate under increasing drift values. Frame \#4 started with a higher rate that decreased with increasing drift values. Repeated cycles showed that the frames could not sustain their energy dissipation capacity. Although they failed under different failure mechanisms, both frames dissipated similar amounts of energy. If bare and infill frames are compared, the frames with infill walls dissipated higher amounts of energy at the corresponding drift values at the $1^{\text {st }}$ story.

The stiffness degradations of the tested frames for both loading cycles at each drift level are presented in Fig. 7. The stiffness values presented in the figure are normalized by the initial stiffness of each frame. The infill frames started with higher stiffness values but these values decreased faster than those of the bare frames. The secondary loading cycles had lower stiffness values. Except for Frame \#1, the stiffness degradation of the frames in the secondary cycles remained roughly parallel to the primary loading cycles. The secondary cycles of Frame \#1 had increasing differences. It should be noted that at about $2 \%$ interstory drift ratio, even after sustaining heavy damages, the stiffness values of the infill frames are about twice as much as those of the bare frames.

The envelope curves of the lateral load hysteresis for both bare and infill frame couples are presented in Fig. 8. Bare frames do not show any major deterioration except for the last cycle of Frame \#1. A strength deterioration of $16 \%$ between the primary and secondary loading cycles took place. The frames with infill walls have higher deteriorations within their primary cycles and between their primary and secondary cycles. The maximum 


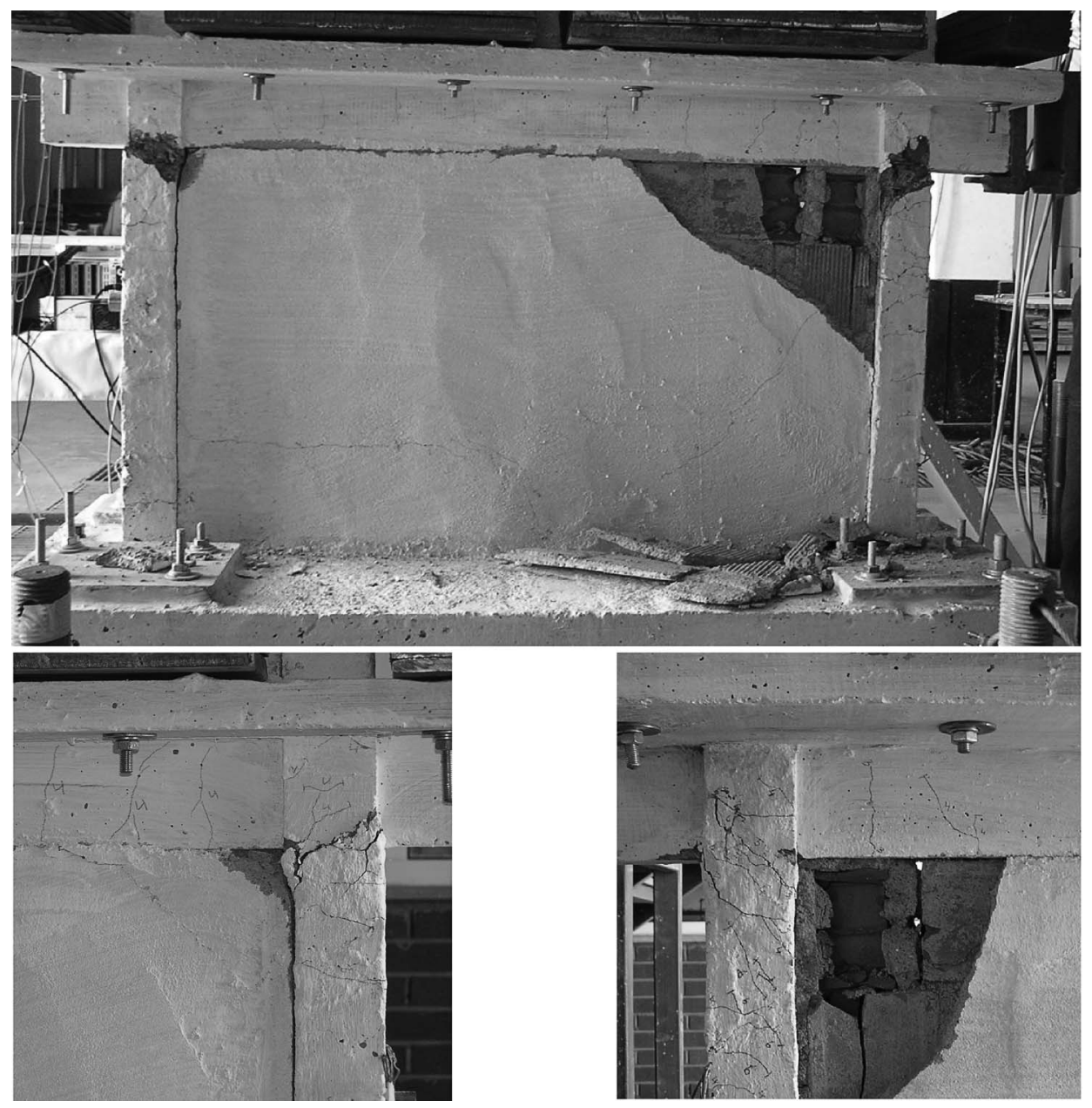

FIGURE 5 The damage in the $1^{\text {st }}$ story of Frame \#4 after the $6^{\text {th }}$ loading group. The figures at the bottom are pictures of the corresponding joints from the other face.
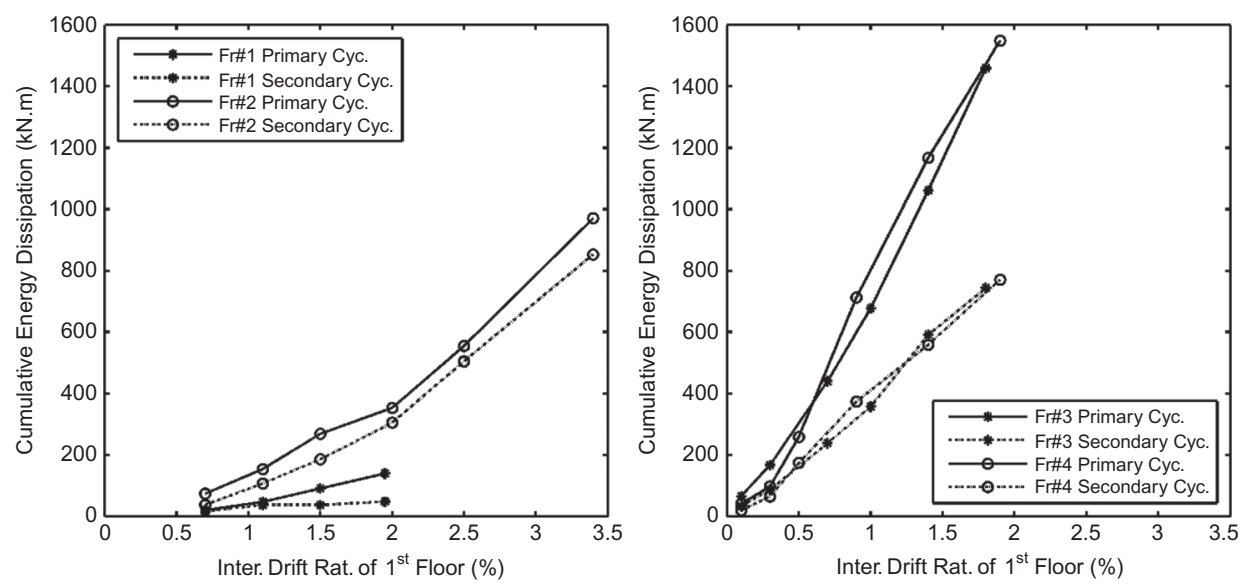

FIGURE 6 The cumulative energy dissipation in the tested frames. 


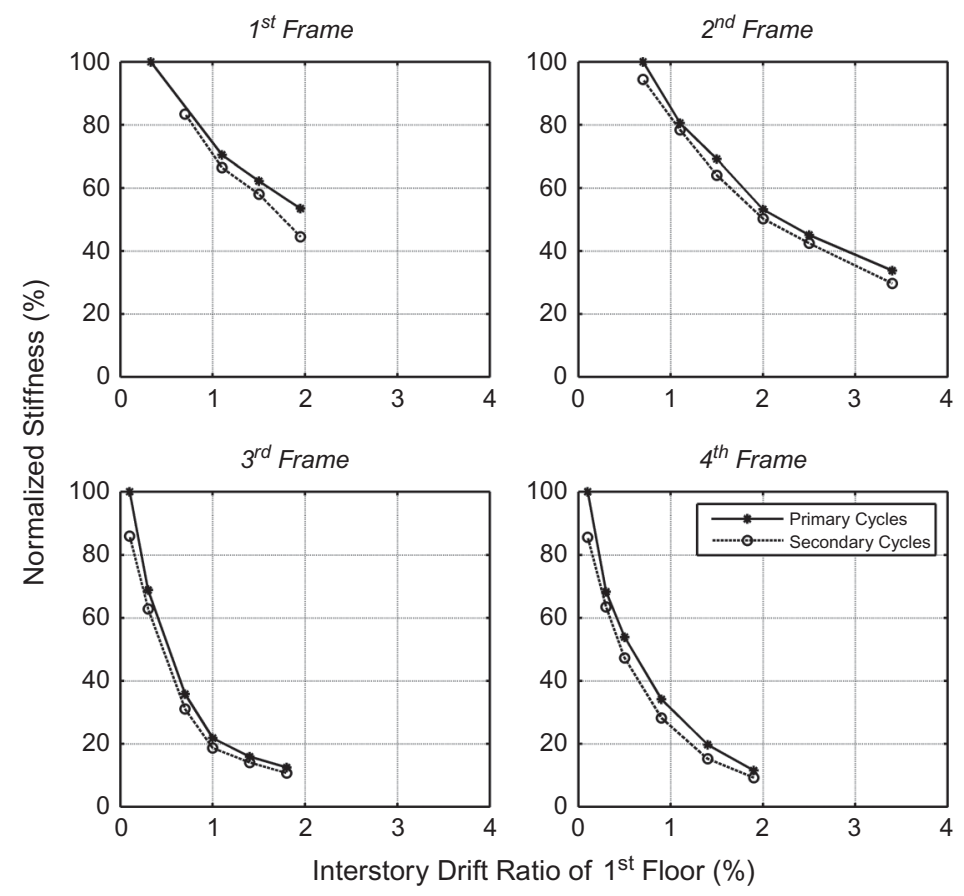

FIGURE 7 The stiffness degradation of the tested frames.

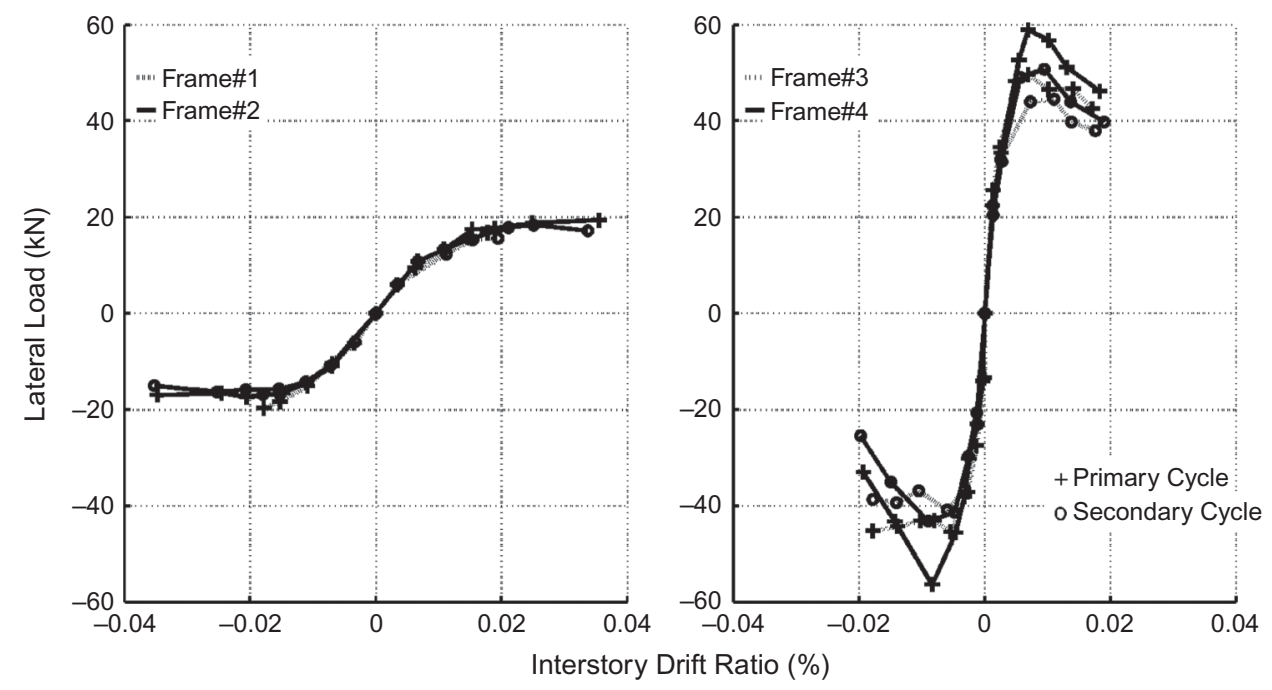

FIGURE 8 The lateral load bearing deterioration in the tested frames.

values are $14 \%$ and $42 \%$ within the primary cycles, and $12 \%$ and $24 \%$ between the primary and secondary cycles for Frame \#3 and Frame \#4, respectively. Frame \#3 did not lose its load capacity in the east direction (negative load area in Fig. 8). The loading cycles of the frames started towards west and continued to the east direction. The observed load levels indicate that the frame did not reach the same load levels in each direction. The bedjoint sliding mechanism formed within the wall, after maximum loading in west direction, 
resulted in a lower maximum and non-deteriorating load behavior in the east direction. It should be noted that the lateral load level reached in the last cycle of the west direction was comparable with the load sustained in the east direction.

\subsection{Drift Behavior Under an Applied Load Profile}

The base shear vs. the average drift ratio hysteresis of the tested frames are presented in Fig. 3. It can be observed that Frame \#2 had a higher drift capacity than that of Frame \#1. Frames with the infill walls reached to lower average drift ratios. Both frames had drift ratios below $1 \%$. To observe the shear versus the drift relation at the local level, the corresponding relations in the $1^{\text {st }}$ story of the frames are presented in Fig. 9. As the figure shows, Frames \#1 and \#2 reached drift ratios of approximately $2 \%$ and $3.5 \%$, respectively. The drift ratios in Frames \#3 and \#4 were in the neighborhood of 2\%. A comparison of the average and the $1^{\text {st }}$ story interstory drift ratios indicates that the upper floors of the frames with infill walls contribute less to the total drift than those of the bare frames. This can be explicitly observed from Fig. 10, which shows the interstory drift ratios of all the floors at the peak load of every loading cycle. The figure shows that the deformations are relatively well distributed through the height in the bare frames at the initial cycles. There is a tendency to increase for the interstory drift ratios of all floors, but the drift was concentrated in the lower stories as the damage progressed. Concentration of the drift in frames with infill walls is more dramatic such that a soft story started to form in the $1^{\text {st }}$
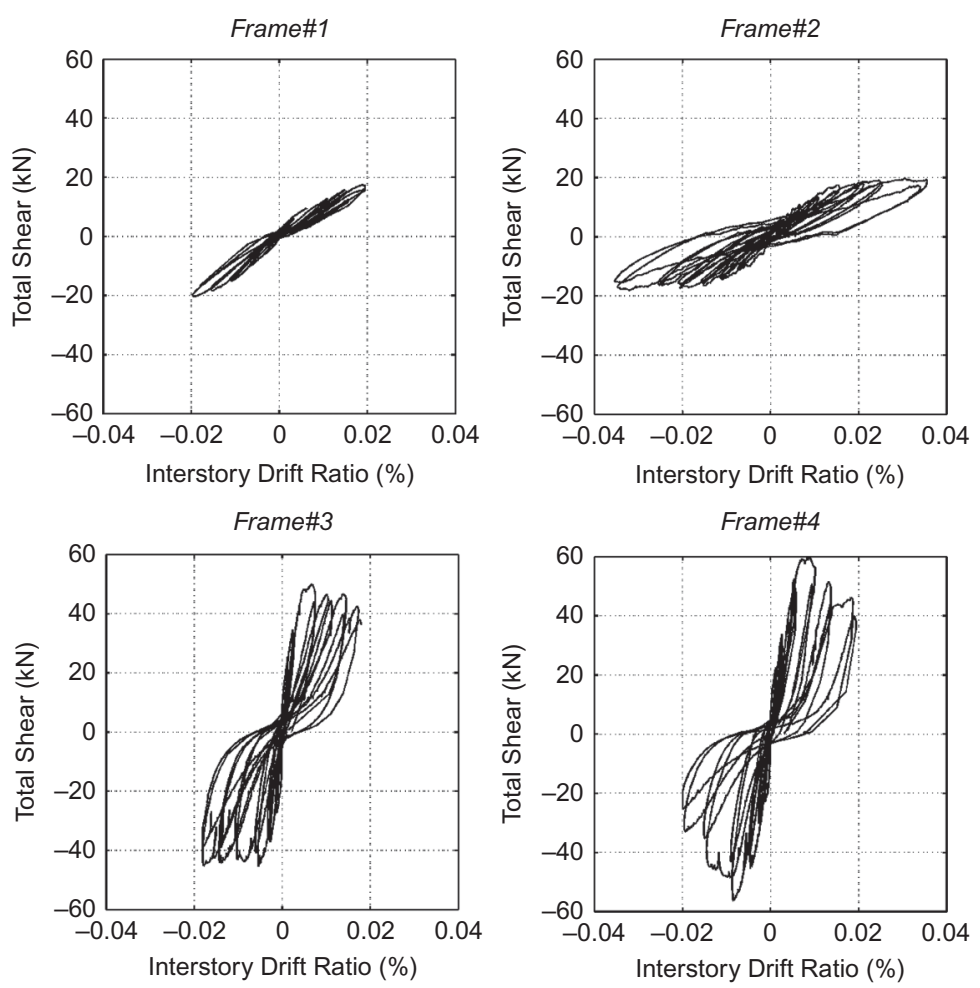

FIGURE 9 The $1^{\text {st }}$ story interstory drift ratio versus the total base shear hysteresis of the frames. 


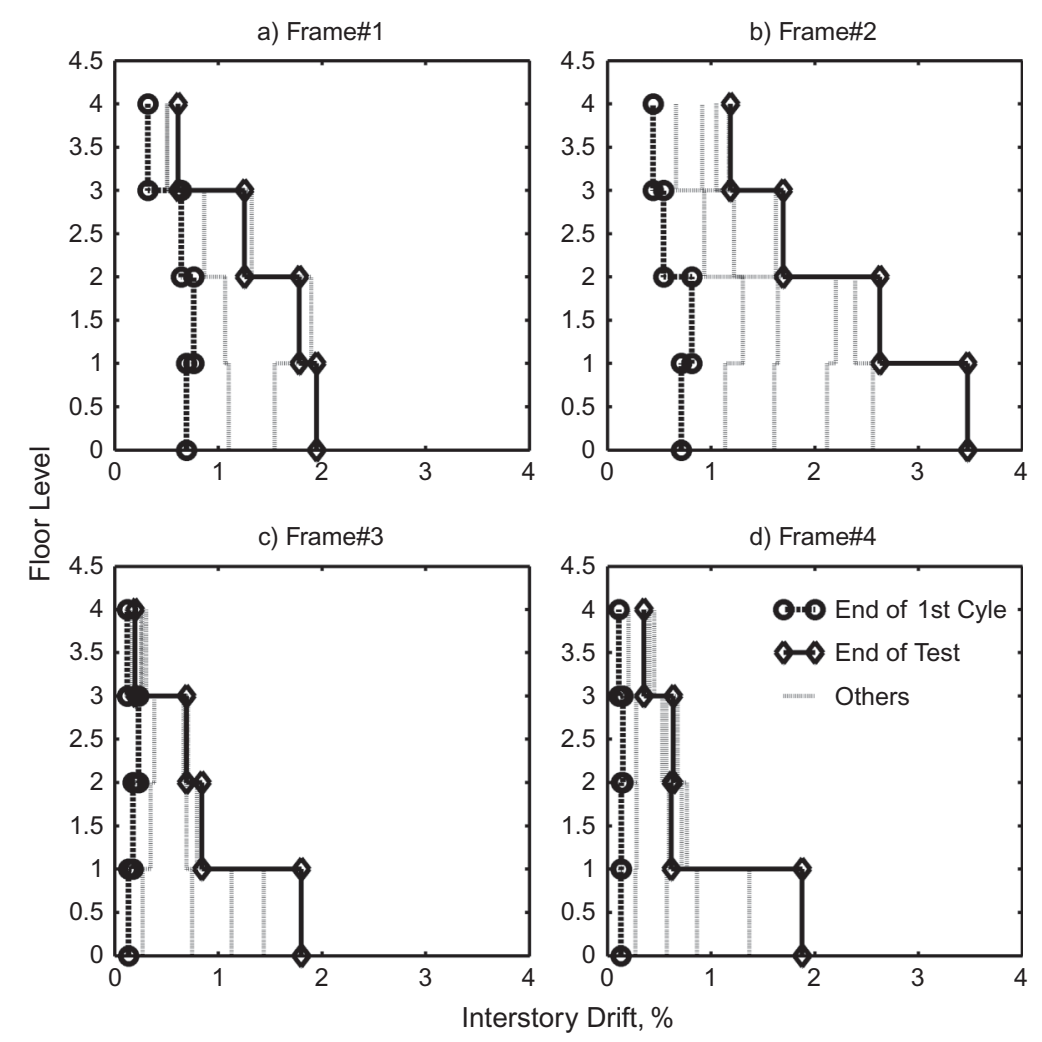

FIGURE 10 The interstory drift ratios of the frames under applied loading at the peak strength of each loading cycle.

story beyond a $0.75 \%$ drift ratio. After this value was reached, contribution of the upper floors to the total drift decreased significantly compared to that of the bare frames.

\section{Impact Hammer Tests}

Experiments were designed to estimate the dynamic parameters of the test frames at different damage levels. Experimental modal analysis techniques were used to obtain the dynamic parameters. The frames were excited with a $11.5 \mathrm{~kg}$ impact hammer at the $4^{\text {th }}$ story level. The accelerations at the story levels and the column mid-heights were recorded with a total of 9 accelerometers under the given excitation.

It should be noted that one of the main assumptions in the experimental modal analysis is that the system considered is linear [Allemang, 1999a,b]. However, the frames tested in this study were in the nonlinear range of their material response. The verification of linearity assumption for the purpose of modal analysis was satisfied after observing the frequency response functions. An analysis of the recorded accelerations showed that even though the dynamic characteristics of the frames change because of the damages induced by each cycle, the dynamic response between the cycles could be accepted as linear to obtain the dynamic parameters under a certain frequency. A detailed explanation of the performed modal experiment and analysis can be found in Cankaya [2011]. The complex mode indicator function of the X-Modal experimental modal analysis software [X-Modal, 2007] 


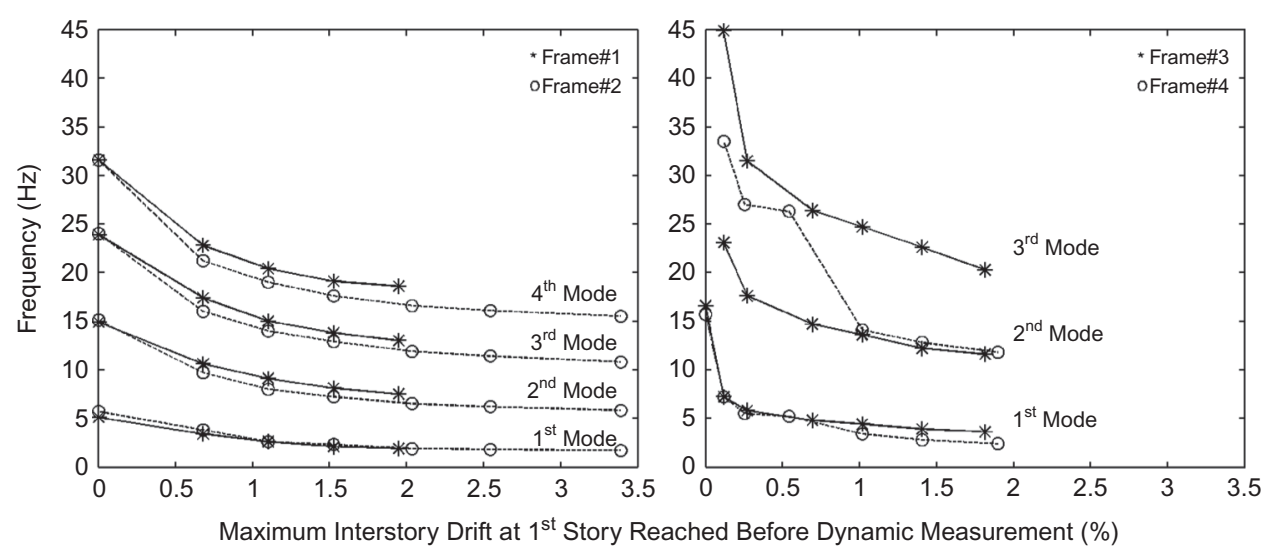

FIGURE 11 The variation of the natural frequencies of the tested frames estimated by the impact hammer test data.

was used to estimate the dynamic parameters of the system. The discussion presented here will be limited to the estimated natural frequencies and the modal shapes of the frames only.

\subsection{The Estimated Natural Frequencies of the Frames}

The natural vibration frequencies of the bare frames in the first four modes are presented in Fig. 11. If the frequencies of the bare frames are compared, it can be observed that the cycle basis values are close to each other and have similar variation trends with increasing damage. The first mode of Frame \#1 has a frequency of $5.1 \mathrm{~Hz}$ at the beginning of the test. By the end of the fourth cycle, it decreases to $1.9 \mathrm{~Hz}$. The second, third and fourth modes have frequencies of 14.9, 23.9, and $31.6 \mathrm{~Hz}$, respectively, at the beginning. By the end of the fourth cycle, the frequencies decreased to 7.5, 13.0, and $18.6 \mathrm{~Hz}$, respectively. In general, the decrease in frequency slowed with increasing drift. Frame \#2 has frequency values of $5.7,15.1,24.0$, and $31.6 \mathrm{~Hz}$ at the beginning of the test for the $1^{\text {st }}-4^{\text {th }}$ modes, respectively. By the end of the $6^{\text {th }}$ cycle, the frequencies decreased to $1.7,5.8,10.8$, and $15.5 \mathrm{~Hz}$.

Because of the difficulty in exciting the system at high frequencies and the increased noise with increasing material nonlinearity, only the first three modes for Frame \#3 and the first two modes for Frame \#4 were estimated. In the undamaged condition, the $2^{\text {nd }}$ and $3^{\text {rd }}$ mode values of both frames were not estimated because of the difficulty in exciting higher frequencies. The frequencies of the $1^{\text {st }}$ mode have values of 16.6 and $15.7 \mathrm{~Hz}$ at the beginning and 3.6 and $2.4 \mathrm{~Hz}$ at the end of the $6^{\text {th }}$ cycle for Frames \#3 and \#4, respectively. Frequency values of the both frames are in the close proximity up to the $3^{\text {rd }}$ cycle. The separation started at the fourth cycle, which was the start of the heavy diagonal cracking at the column heads at the $1^{\text {st }}$ story of Frame \#4. Although the frames with the infill walls had larger decrease in frequency, they had higher frequencies at the end of the tests. The frequency ratios of the infill wall to the bare frames at the end of the tests were 2.0 for Frames \#1 \& \#3 and 1.4 for Frames \#2 \& \#4.

\subsection{The Estimated Modal Shapes and the Drift Behaviors of the Frames}

The modal shapes of the frames at the end of each loading cycle, reported in Table 2, were estimated by modal analysis techniques. To compare them, the modal shapes were 

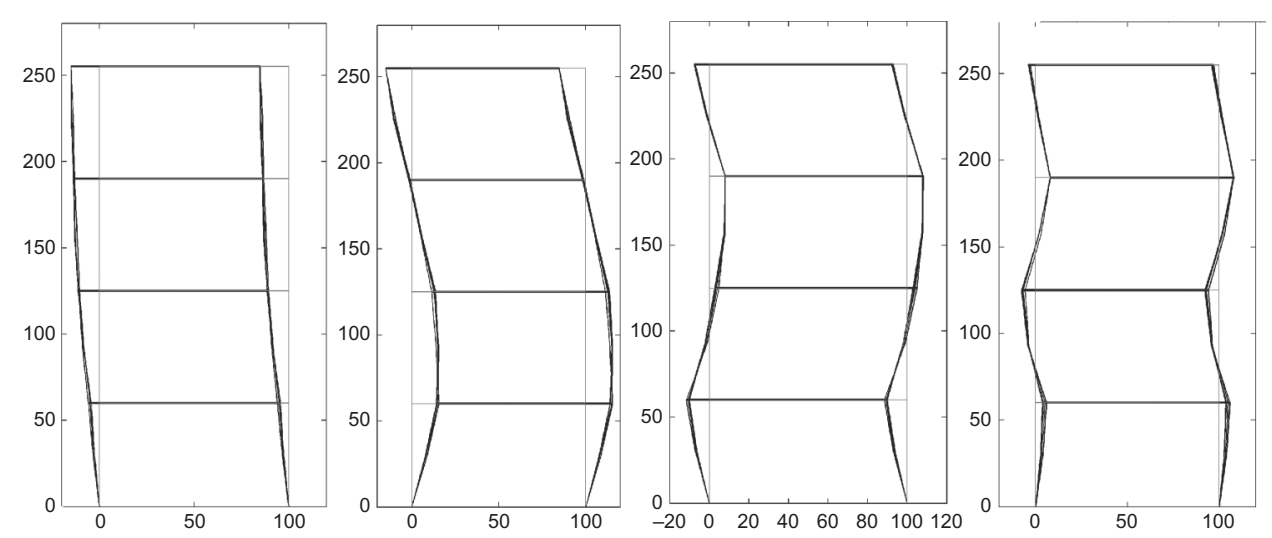

FIGURE 12 The modal shapes of Frame \#1, estimated after every loading cycle. (a) $1^{\text {st }}$ mode; (b) $2^{\text {nd }}$ mode; (c) $3^{\text {rd }}$ mode; (d) $4^{\text {th }}$ mode.
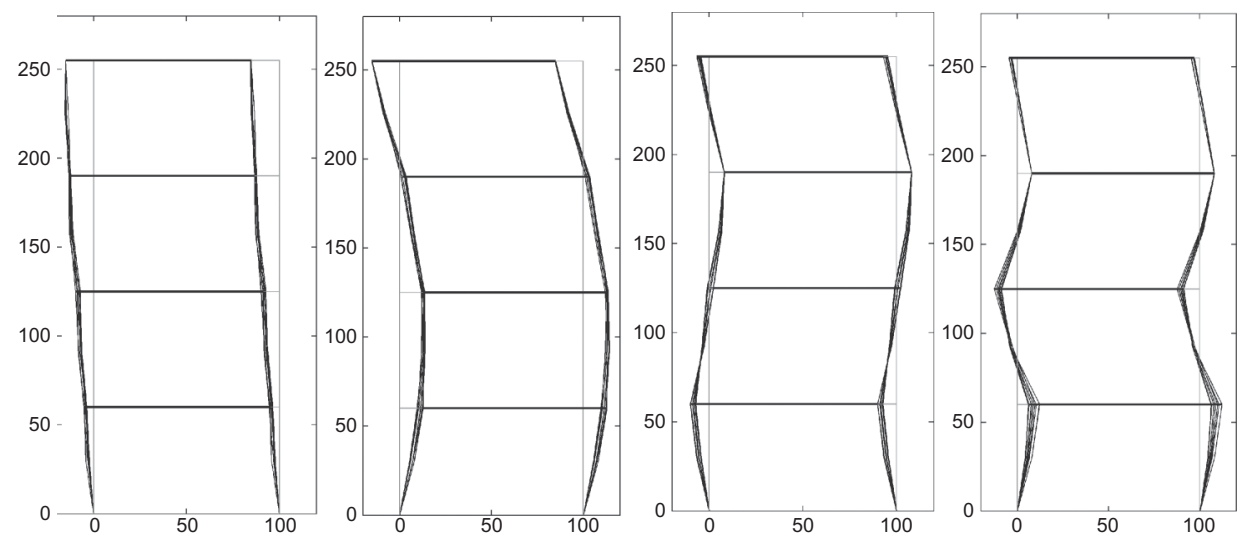

FIGURE 13 The modal shapes of Frame \#2, estimated after every loading cycle. (a) $1^{\text {st }}$ mode; (b) $2^{\text {nd }}$ mode; (c) $3^{\text {rd }}$ mode; (d) $4^{\text {th }}$ mode.

normalized to have a displacement of 10 units in the fourth floor for the $1^{\text {st }}$ and $2^{\text {nd }}$ modes and a displacement of 5 units in the third floor for the $3^{\text {rd }}$ and the $4^{\text {th }}$ modes. The modal shapes for the first four modes of Frame \#1 are presented in Fig. 12. It should be noted that the modal shapes presented in the figure include estimations for the uncracked condition and for the conditions after every loading group. As an example, Fig. 12a includes five different modal shapes on top of each other that are corresponding to the natural frequencies of the $1^{\text {st }}$ mode. Similarly, the modal shapes for the first four modes of Frame \#2 are presented in Fig. 13. The figure shows that, even though there is a similar trend, the variations are stronger. A judgment that is based only on the modal shape figures leads to the conclusion that there is no significant change with increasing damage. Re-examining the first mode modal shapes by calculating the interstory drift ratios presents a different picture. The calculation of the mass participation ratio of the $1^{\text {st }}$ modes indicates that participations were in the $90 \%$ range. Therefore, the $1^{\text {st }}$ modes of the frames can be used to represent the global drift behavior. For this purpose, the vectors of the first modes are scaled to the maximum average drift reached in the loading cycle prior 
a) Frame\#1

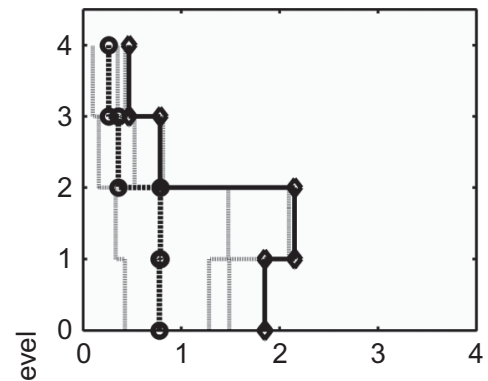

c) Frame\#3

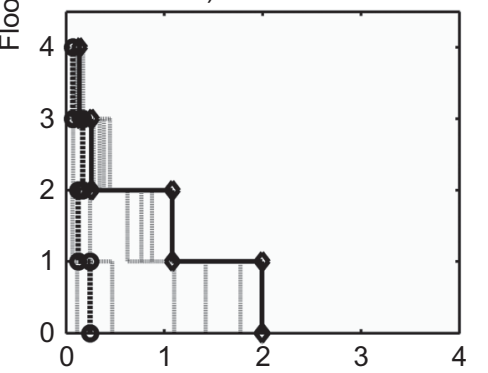

b) Frame\#2

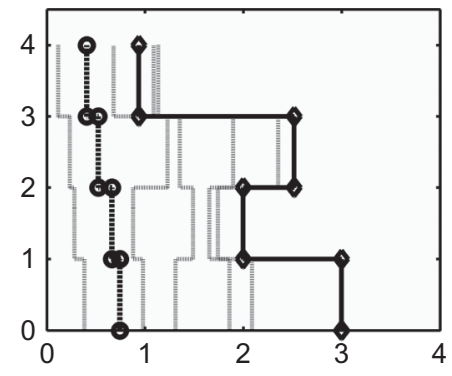

d) Frame\#4

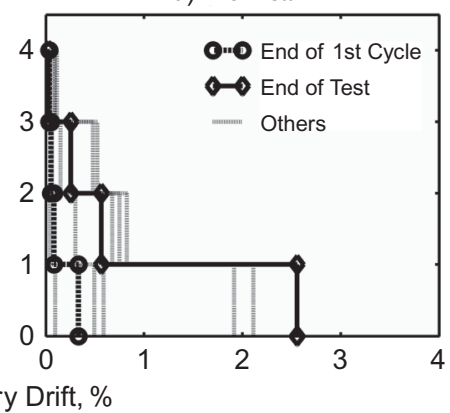

FIGURE 14 The interstory drifts of the frames obtained by normalizing the average drifts of the $1^{\text {st }}$ modes by the maximum average drifts reached in the corresponding loading cycles.

to the impact tests and the interstory drift ratios are calculated based on these vectors. The results are presented in Figs. 14a and b. A strong correlation between the interstory drift ratios and the damage at the floor levels is observed. A comparison of the new drift distributions with the distributions under applied loads (Fig. 10) indicates that, in contrast to the former case there is no uniform increase in the drift ratios along the height of the frames with increasing damage. The drift appears to be concentrated at the lower levels with the exception of the jump at the $3^{\text {rd }}$ floor in Frame \#2.

The modal shapes corresponding to the first three modes of Frame \#3 are presented in Fig. 15. Compared to that of bare frames, a larger variation in the $1^{\text {st }}$ mode of Frame $\# 3$ is observed. The $2^{\text {nd }}$ and $3^{\text {rd }}$ modes had significant variations, which can be seen in Figs. 12, 13, and 15. Frame \#4 followed a similar trend, with further disfigurement related to initiation of heavy diagonal cracks at the $1^{\text {st }}$ floor columns (Fig. 16). The interstory drifts ratios based on the first mode of Frames \#3 and \#4 are calculated by the same procedure used for bare frames. The results are presented in Figs. 14c and d. The concentration of drift in the lower stories was observed to intensify with increasing damage. There is a higher contribution from the $2^{\text {nd }}$ story of Frame \#3 compared to that of Frame \#4. This is consistent with the observed damage in infill of the $2^{\text {nd }}$ story in Frame \#3. On the other hand, the observed drift contribution from the $3^{\text {rd }}$ floor in the forced case (Fig. 10) vanishes. Compared to Frame \#3, Frame \#4 has a higher concentration of drift in the $1^{\text {st }}$ floor. The progress of the concentration follows the heavy diagonal cracks in the $1^{\text {st }}$ floor. Starting with the $4^{\text {th }}$ loading cycle, at which full penetration of the diagonal cracks were completed, the $1^{\text {st }}$ story dominated the drift distribution of Frame \#4. 

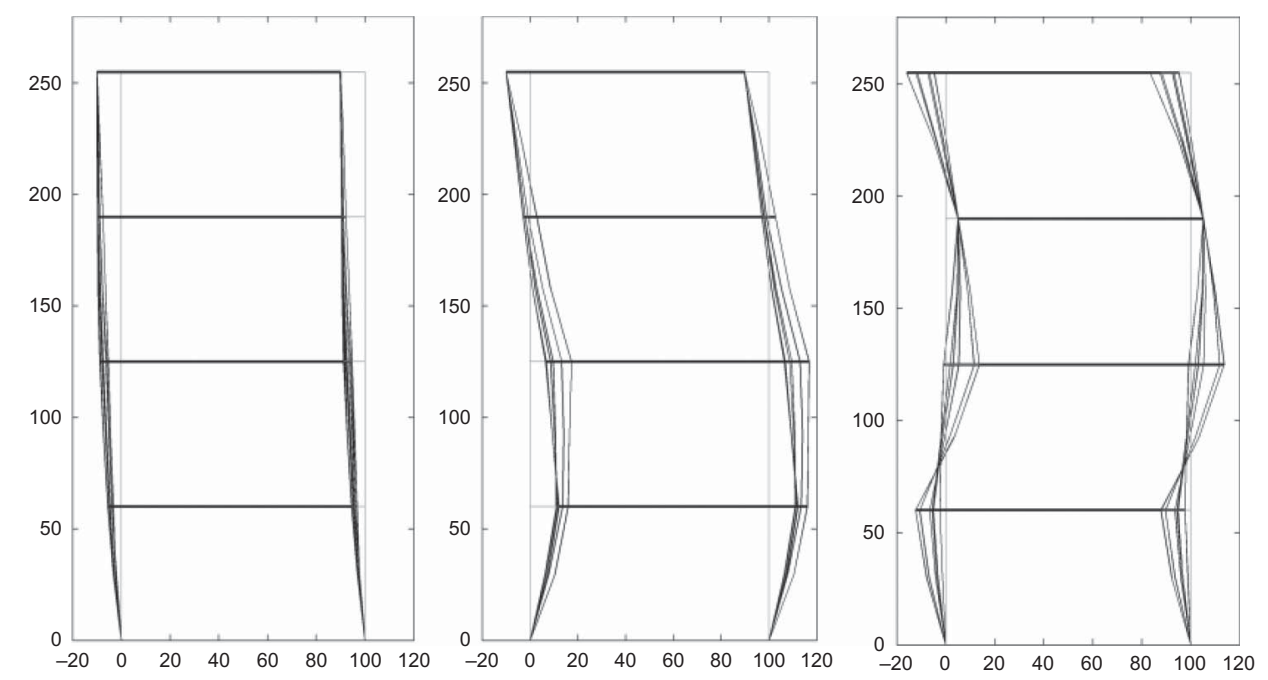

FIGURE 15 The modal shapes of Frame \#3 estimated after every loading cycle. (a) $1^{\text {st }}$ mode; (b) $2^{\text {nd }}$ mode; (c) $3^{\text {rd }}$ mode.
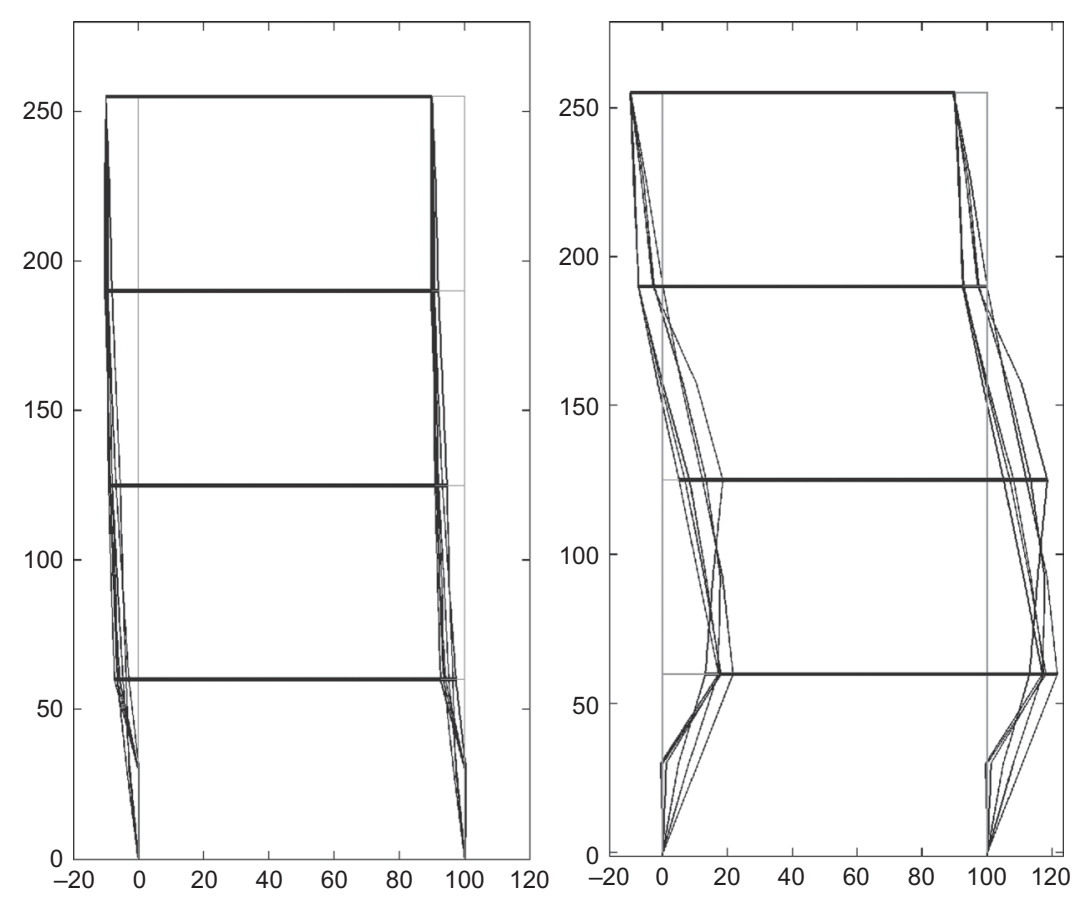

FIGURE 16 The modal shapes of Frame \#4 estimated after every loading cycle. (a) $1^{\text {st }}$ mode; (b) $2^{\text {nd }}$ mode.

\section{Discussion of the Results}

As presented in the text, the interstory drift ratios of the tested frames are calculated by two different approaches: (1) by using the deformation profiles that are obtained at the peak strength of the frames (Fig. 10) and (2) by using the scaled $1^{\text {st }}$ modes of the frames by the 
maximum deformation reached at every cycle (Fig. 14). The interstory drift ratios based on the forced deformation profiles typically increase uniformly with increasing height and damage. This behavior is not repeated in the story-drift ratios that are based on the $1^{\text {st }}$ modes of the frames. For this case, except for Frame \#2, the drift contribution of the two upper floors decreased significantly. The drift in the modal-shape-based distribution is observed to be closely correlated to the existing damage in the frames. Considering that the inverted triangle force distribution is used in the performance based design under seismic loads, further discussion and verification is needed regarding the variation of drift distribution under this loading profile.

The test results demonstrated that Frames \#3 and \#4 reached their capacities by different failure mechanisms. A simple analysis by using of free body diagrams formed by cutting the frame above the first story columns provides insight into the cause of the difference. As it is presented in Fig. 17, the equilibrium of the upper body requires the sum of the loads transferred from the upper stories, the column internal forces, and the shear along the $1^{\text {st }}$ story beam infill wall interface to be zero. In Fig. 17, a simple representation of the compression strut in the infill wall is also presented. The loads transferred from the upper stories can be readily calculated by the measured lateral loads and by calculating the self-weight and any additional weights. The corresponding values of these forces at the maximum lateral force, as well as the available sectional capacities of the first story columns are presented in Table 3.

To satisfy the moment equilibrium of the upper body, the moment of the force couple formed by the axial loads should be equal to the sum of the moments (see Fig. 17). At the peak load, the strain gage readings indicate that all of the bars of the tension column yielded in Frame \#4. Therefore, the total moments are calculated by adding the yield moment of both columns in Frame \#3 and only the compression column in Frame \#4. Ignoring the possible contribution of the infill wall to the compression force, the moment arm of the couples is taken as $1.0 \mathrm{~m}$. Hence, the couple forces are 73.0 and $84.0 \mathrm{kN}$ for Frames \#3 and \#4, respectively. After subtracting the effect of gravity loads, the axial loads in the tension columns become 61 and $72 \mathrm{kN}$, respectively. Noting that the total tensile strength of the

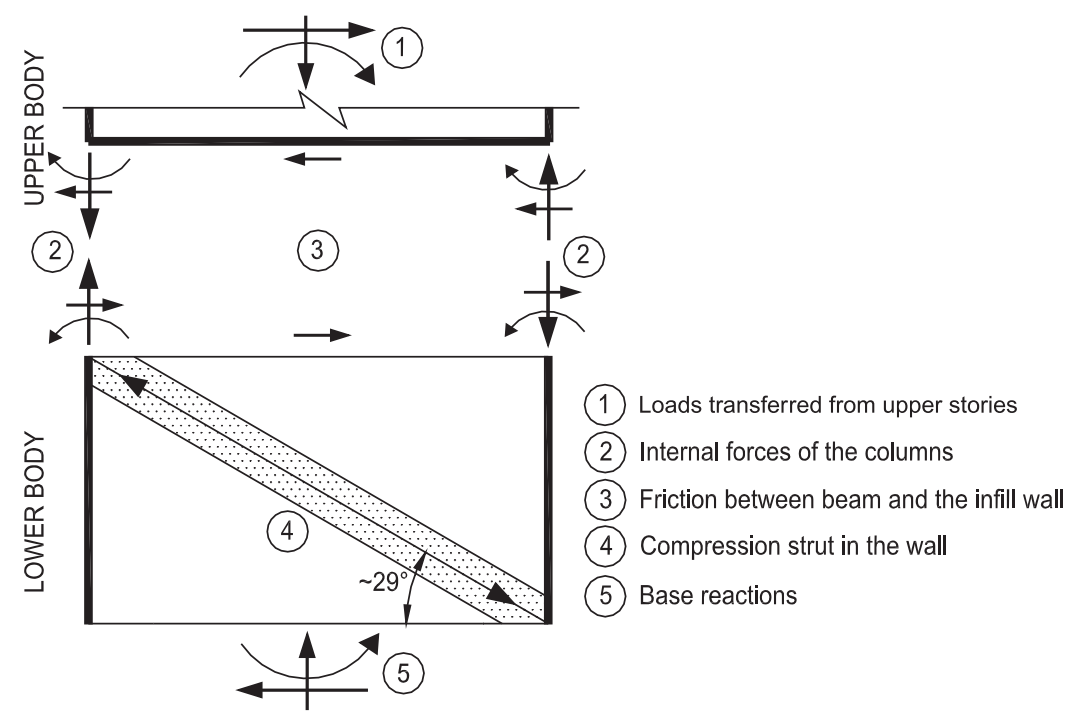

FIGURE 17 Free body diagrams by a section cut at the interface between the $1^{\text {st }}$ story columns and the beam. 
TABLE 3 The loads transformed from the upper body and the section capacities of the $1^{\text {st }}$ story columns

\begin{tabular}{lcc}
\hline & Frame \#3 & Frame \#4 \\
\hline Upper Body & & \\
Total Lateral Force $(\mathrm{kN})$ & 49.5 & 59.6 \\
Overturning Moment (kN.m) & 67.7 & 81.4 \\
Gravity Load (kN) & 23.0 & 23.0 \\
$1^{\text {st }}$ Story Columns & & \\
Yield Moment (kN.m) & 2.45 & 2.35 \\
Tensile Strength $(\mathrm{kN})$ & 96.0 & 96.0 \\
Shear Strength $(\mathrm{kN})$ & 22.7 & 36.3 \\
\hline
\end{tabular}

columns is $96 \mathrm{kN}$, a limited capacity is left to support the formation of a compression strut tension tie mechanism in the column. The angle of inclination of the strut is approximately $29^{\circ}$ (Fig. 17), and the maximum possible forces in the struts are calculated to be 72 and $49 \mathrm{kN}$ for Frame \#3 and \#4, respectively. Hence, the maximum possible horizontal forces that can be developed by the infill struts are 63 and $43 \mathrm{kN}$, respectively.

Similarly to satisfy the horizontal force equilibrium, the sum of the external forces should be equal to the horizontal forces at the columns and the beam wall interface (Fig. 17). For Frame \#4, based on the observations that the tension column yielded and the infill-wall stayed integral, the tension column and the compression strut in the wall can develop a maximum horizontal resistance of $43 \mathrm{kN}$. The compression column developed plastic hinges at its ends and only contributed $9 \mathrm{kN}(2.35 \times 2 / 0.53)$ to the shear resistance. Hence, the rest of the lateral force was resisted by the friction at the beam infill-wall interface. This corresponds to a $7.6 \mathrm{kN}$ shear force and a $0.10 \mathrm{MPa}$ average shear stress on the sliding surface. It could be concluded that upon reaching the yield strains and beyond in the reinforcement, diagonal cracks enlarged and the column-infill-wall strut mechanism reached its capacity. The observed formation of cracks in the failure zone (Fig. 5) supports the discussed mechanism. As previously stated, the $1^{\text {st }}$ story infill wall kept its global integrity except for corner crushing at the last two cycles and main drift took place in the form of sliding of the upper body of the frame on the infill wall. The effect of this softening on the $1^{\text {st }}$ floor was evident in the interstory drift ratios on the $1^{\text {st }}$ mode of the frame. The $1^{\text {st }}$ story drift ratio was 5 times that of the $2^{\text {nd }}$ story.

It should be noted that the infill wall in Frame \#4 kept its integrity and forced the column to yield because of its high shear capacity. Based on the performed diagonal compression tests, the infill wall can provide $62 \mathrm{kN}$ of total resistance before failure. This value is larger than $43 \mathrm{kN}$, which is sufficient to cause tension yielding of the column.

The $1^{\text {st }}$ story columns of Frame \#3 reached their peak capacities at a measured lateral load of $49.5 \mathrm{kN}$. The maximum capacity of the frame was reached just before the formation of the bed-joint sliding cracks in the $1^{\text {st }}$ story infill wall. The strain gauge readings, the level of lateral load and the observed damage in the infill walls indicated that the tension column of Frame \#3 did not pass its tension yield capacity. As presented in the preceding paragraphs, the tension column had the potential capacity to develop $63 \mathrm{kN}$ of horizontal shear through the column-infill-wall strut mechanism. On the other hand, based on the performed diagonal compression tests, the shear capacity of the infill wall is calculated to be $25 \mathrm{kN}$. Therefore, column had the capacity to force the infill wall beyond its shear capacity. Although the diagonal cracks similar to that of Frame \#4 initiated at the column ends during the test, they did not progress to form full-penetration diagonal cracks. The 
hysteresis curves show that the $1^{\text {st }}$ story maintained its capacity in spite of the widespread cracking in the frame members and the infill wall. Therefore, the damage and the drift in the frame extended to the $2^{\text {nd }}$ story. The effect of softening in the bottom two stories was evident in the interstory drift ratios that are based on the $1^{\text {st }}$ mode of the frame. The first story drift ratio was observed to be twice that of the $2^{\text {nd }}$ story.

Even though both frames with infill walls developed soft stories at the $1^{\text {st }}$ floor, the drift demands in the $1^{\text {st }}$ story of Frame \#4 reached higher values. Both of the tested frames managed to sustain maximum interstory drift ratios of approximately $2 \%$ at the first floor and an average drift ratio of less than $1 \%$. Considering that Frame \#4 had better reinforcement detailing, its overall observed behavior is accepted to be inferior to that of Frame \#3.

The effect of reinforcement detailing of the frames on the behavior was minimized because of the higher concrete strengths attained. Slip of the longitudinal bars, shear failure of the columns or the opening of the $90^{\circ}$ hooks of the stirrups, were expected to be observed. However, no such failures were observed because of the higher shear and bond strengths as a result of the high concrete strengths. Both of the bare frames sustained similar lateral loads as a result of failures controlled by moment capacities. The effects of detailing was evident in the cumulative energy dissipation of Frame \#1 (Fig. 6a) and the higher drift value reached by Frame \#2. The failure of the infill frames was controlled by the mobilization level of the infill capacities. The lower story infill shear capacity permitted the perimeter frame in the $1^{\text {st }}$ story to use the infill capacity to its advantage in Frame \#3. The framing in the $1^{\text {st }}$ story reached the drift capacity attained by Frame \#1 and reached higher lateral load levels. In Frame \#4, the higher infill shear capacity caused the premature failure of the $1^{\text {st }}$ story perimeter frame. Although ductile detailing improved the overall behavior, the drift levels of the $1^{\text {st }}$ story could not reached the levels reached by Frame $\# 2$.

\subsection{Future Work}

Based on the observations of previous work and the current study, it can be concluded that avoiding drift concentrations at lower stories could improve the seismic response of RC frames with infill walls. Estimating the strength and stiffness relation between the neighboring floors is necessary to coordinate a satisfactory drift distribution along the height of the frames. The existing literature shows that it is not an easy task to estimate the strength and stiffness of an infill wall because of complexities about the material and the workmanship. One way to solve this problem can be the infusion of controlled weaknesses to infill walls to control their strength and stiffness. There is an existing study that investigated methods to increase the ductility of the infill walls by supplying sliding fuses [Mohammadi et al., 2011]. A similiar approach could be adopted to control the relative strength and stiffness of the neighboring floors to avoid drift concentration.

\section{Conclusions}

The test results indicate that infill walls have a significant effect on the strength, stiffness, and drift behavior of the RC frames subjected to lateral load reversals. It was observed that the natural frequencies of the tested frames decreased with increasing damage. The decrease in the frequencies of the frames with infill walls was more significant, but the frequency values were still higher than those of the bare frames at the corresponding interstory drift levels at the $1^{\text {st }}$ story. It is well established that the sufficient drift capacity of a structure under earthquake demands is mainly a function of its dominant natural frequency. Therefore, deciding the sufficient drift capacity of a RC structure with infill walls should be based on the frequency value that is obtained by considering the effect of the infill walls. 
This study shows that the concentration of drift due to the local damage could be very dramatic for frames with infill walls. Hence, the story drifts should be investigated rather than the average drifts to make structural decisions.

The higher natural frequencies sustained by frames with infill walls could result in a decrease in the seismic drift demand of the structure. This behavior indicates a potential for a possible seismic mitigation approach. The mobilization of such a potential necessitates matching the drift capacity to the drift demand. The test results show that even though locally higher drift values could be attained, the concentration of drift could result in premature failures of the frames without satisfying the drift demands. Hence, means and methods to avoid the local concentration of drifts should be developed.

It is observed that the compartmentalized construction and the brittle behavior of the infill walls result in a discrete failure sequence among the floors that are controlled by the strength and stiffness interrelation. If the infill wall of a story starts to soften, the drift starts concentrating in that story because of the decrease in stiffness. If the failure mode of the wall causes a large decrease in the strength of the floor and/or the floor does not sustain sufficient capacity to trigger the softening of the neighboring floor, further drift takes place. Therefore, depending on the post stiffness value and the gap between the strength levels of the neighboring floors, the softening floor may need to contribute higher drift amounts and the whole system could fail at early average drift levels for the structure.

The frames both with and without infill walls had similar frequency values for the first mode within each group. Direct observations of the mode shapes with progressing damage did not reveal change in the drift behavior of the frames. Presenting the data in an interstory drift ratio format was found to be more effective. The observed sensitivity of the modal shape based interstory drifts to the damage in the tested frames could be utilized for structural monitoring purposes.

It is observed that the interstory drift ratio distribution of the forced deformation profile and the $1^{\text {st }}$ mode shape profile have different characters. The mode shape based values were more sensitive to the damage distribution in the test frames and reflect stronger soft story formations. Considering that forced loading profiles are used in performance-based design under seismic loads, further discussion and verification are needed regarding the differences of drift distribution under both static and dynamic conditions.

\section{Acknowledgments}

This study was conducted at the Structural Mechanics Laboratory of Izmir Institute of Technology. The research is supported by the Scientific and Technological Research Council of Turkey (TÜBITAK) under grant MAG-104I107.

\section{References}

Allemang, R. J. [1999a] Vibrations II: Analytical and Experimental Modal Analysis, UC-SDRL-CN20-263-662, University of Cincinnati, Cincinnati, Ohio.

Allemang, R. J. [1999b] Vibrations III: Experimental Modal Analysis, UC-SDRL-CN-20-263663/664, University of Cincinnati, Cincinnati, Ohio.

Angel, R., Abrams, D., Shapiro, D., Uzarski, J., and Webster, M. [1994a] "Behavior of reinforced concrete frames with masonry infills," Civil Engineering Studies, University of Illinois, Urbana, Illinois, SRSS-589.

Applied Technology Council, ATC-43, Project. [1999] Evaluation of Earthquake Damaged Concrete and Masonry Wall Buildings-Basic Procedures Manual, prepared for the partnership for Response and Recovery, FEMA-306, Washington D.C.

Calvi, G. M. and Bolognini, D. [2001] "Seismic response of reinforced concrete frames infilled with weakly reinforced masonry panels," Journal of Earthquake Engineering 5(2), 153-185. 
Cankaya, M. A. [2011] "Dynamic behavior of reinforced concrete frames with infill walls," MS thesis, Civil Engineering Dept., İzmir Institute of Technology, İzmir, Turkey

Dolsek, F. [2001] "Soft storey effects in uniformly infilled reinforced concrete frames," Journal of Earthquake Engineering 5(1), 1-12.

Dolsek, M. and Fajfar, F. [2002] "Mathematical Modelling of an Infilled RC frame structure based on the results of pseudo-dynamics tests," Earthquake Engineering \& Structural Dynamics 31, $1215-1230$.

Dolsek, M. and Fajfar, F. [2008] "The effect of masonry infills on the seismic response of a four-storey reinforced concrete frame-a deterministic assessment," Engineering Structures 30, 1991-2001.

Erdem, I., Akyüz, U., Ersoy, U., and Özcebe, G. [2006] "An experimental study on two different strengthening techniques for RC frames," Engineering Structures 28, 1843-1851.

Fiorato, A. E., Sözen, M. A., and Gamble, W. L. [1970] "An investigation of the interaction of reinforced concrete frames with masonry filler walls," Civil Engineering Studies, University of Illinois, Urbana, Illinois, UILU-ENG-70-100.

Gerardo, M. V., De Luca, F., Ricci, P., and Manfredi, G. [2011] "Preliminary analysis of a soft-storey mechanism after the 2009 L'Aquila earthquake," Earthquake Engineering \& Structural Dynamics 40, 925-944.

Hashemi, A. and Mosalam, K. M. [2006] "Shake-table experiment on reinforced concrete structure containing masonry infill wall," Earthquake Engineering \& Structural Dynamics 35(14), $1827-1852$.

Lee, S. and Woo, S. [2001] "Effect of masonry infills on seismic performance of a 3-storey R/C frame with non-seismic detailing," Earthquake Engineering \& Structural Dynamics 31, 353-378.

Madan, A., Reinhorn, A. M., Mander, J. B., and Valles, R. E. [1997] "Modeling of masonry infill panels for structural analysis," Journal of Structural Engineering (ASCE) 123(10), 1295-1302.

Mehrabi, A. B., Shing, P. B., Schuller, M. P., and Noland, J. L. [1996] "Experimental evaluation of masonry-infilled RC frames," Journal of Structural Engineering (ASCE) 122(3), 228-37.

Mohammadi, M., Akrami, V., and Mohammadi-Ghazi, R. [2010] "Methods to improve infilled frame ductility," Journal of Structural Engineering (ASCE) 137(6), 646-653.

Negro, P. and Verzeletti, G. [1996] "Effect of infills on the global behaviour of frames: energy considerations from pseudodynamic tests," Earthquake Engineering \& Structrual Dynamics 25(8), 753-773.

Negro, P., Pinto, A.V., Verzeletti, G., and Magonette, G. E. [1996] "PsD test on four-story RC building designed according to eurocodes," Journal of Structural Engineering 122, 1409-1417.

Pinto, A. and Taucer, F. [2006] "Assessment and retrofit of full-scale models of existing RC frames" in Advances in Earthquake Engineering for Urban Risk Reduction, ed. S. T. Wasti and G. Ozcebe (NATO Science Series, Istanbul, Turkey), vol. 66, pp. 353-367.

Pujol, S. and Fick, D. [2010] "The test of a full-scale three-story RC structure with masonry infill walls," Engineering Structures 32, 3112-3121.

Rodrigues, H., Varum, H., and Costa, A. [2008] "A non-linear masonry infill macro-model to represent the global behaviour of buildings under cyclic loading," International Journal of Mechanics and Materials in Design 4, 123-135.

Shapiro, D., Uzarski, J., Webster, M., Angel, R., and Abrams, D. [1994] "Estimating out-of-plane strength of cracked masonry infills," Civil Engineering Studies, University of Illinois,, Urbana, Illinois, SRSS-588.

Smyrou, E., Blandon, C., Antoniou, S., Pinho, R, and Crisafulli, F. [2008] "Implementation and verification of a masonry panel model for nonlinear dynamic analysis of infilled RC frames," Bulletin of Earthquake Engineering 9(5), 1519-1534.

Turkish Seismic Code [2007] Ministry of Public Works and Settlements, Ankara, Turkey.

TS500 [2000] Requirements for Design and Construction of Reinforced Concrete Structures, Ankara, Turkey.

X-Modal [2007] Modal Analysis Software, Structural Dynamics Research Laboratory, University of Cincinnati, Cincinnati, Ohio.

Zarnic, R., Gosti, S., Crewe, A. J., and Taylor, C. A. [2001] "Shaking table tests of 1:4 reducedscale models of masonry infilled reinforced concrete frame buildings," Earthquake Engineering \& Structural Dynamics 30(6), 819-834. 


\section{Appendix A: Scale Effects}

The scaling of the model is dictated by the constraints of the testing facility and the selected parameters. The axial load levels and the frequencies of uncracked frames are taken as the controlling parameters. Similitude laws are followed in scaling as summarized below.

Taking the three basic independent units as length $(\mathrm{L})$, time $(\mathrm{T})$, and force $(\mathrm{F})$, the linear scaling requires the following relations between the units of the test structure and the prototype structure:

$$
\begin{aligned}
& \alpha(L)_{p}=(L)_{m} \\
& \beta(T)_{p}=(T)_{m} \\
& \gamma(F)_{p}=(F)_{m}
\end{aligned}
$$

Here, the subscripts $m$ and $p$ denote the test structure and the prototype structure, respectively. Three constants $\alpha, \beta, \gamma$ are used to show how the length, time, and force are linearly scaled from a prototype to a test structure. $\alpha$ is selected to be $1 / 5$ based on the constraints of the testing facility. To have the same gravitational acceleration field for the test structure and the prototype structure, $\beta$ is determined as

$$
A_{m}=\frac{\alpha}{\beta^{2}} A_{p} \quad ; \text { therefore, } \alpha=\beta^{2} \text { and } \beta=\frac{1}{\sqrt{5}} \text {. }
$$

The value of $\gamma$ is determined to have the same Young's Modulus of elasticity for both the test structure and the prototype structure:

$$
E_{m}=\frac{\gamma}{\alpha^{2}} E_{p} \quad ; \text { therefore, } \gamma=\alpha^{2} \text { and } \gamma=\frac{1}{25}
$$

Based on the selected scaling factors, the other relevant factors for the parameters of the study are as follows:

$$
\begin{aligned}
& \underline{\text { Stress }} \sigma_{m}=\frac{\gamma}{\alpha^{2}} \sigma_{p} \quad ; \text { therefore, } \quad \sigma_{m}=\sigma_{p} \\
& \underline{\text { Strain } \varepsilon_{m}=\frac{\alpha}{\alpha} \varepsilon_{p} ; \text { therefore, } \quad \varepsilon_{m}=\varepsilon_{p}} \\
& \underline{\text { Frequency }} f_{m}=\sqrt{\frac{\left(\frac{\gamma}{\alpha}\right)}{\left(\frac{\gamma}{\frac{\alpha}{\beta^{2}}}\right)} f_{p}} ; \text { therefore, } f_{m}=\sqrt{5} f_{p}
\end{aligned}
$$

OR

$\underline{\text { Period }} P_{m}=\frac{1}{\sqrt{5}} P_{p}$ 


\section{A.1. Moment Capacity}

The moment capacity of a RC section can be calculated if the tension-compression force couple and the moment arm between them are known. As presented in Fig. A1 and Table A1, the location of the resultant tension and compression forces obey the scaling rule in spite of the material nonlinearity. The independence of the stresses from the scaling and the linear formulation of the centroid location and volume calculation of the compression stresses permit such a result. The tension force is self-evident. Considering that the moment is in the form of force*length, the corresponding scaling ratio is $1 / 25^{*} 1 / 5=1 / 125$. As a verification of this analysis, the moment capacities of the test structure and the prototype structure sections are calculated to be $2.5 \mathrm{kN} . \mathrm{m}$ and $306 \mathrm{kN}$.m, respectively. Until now, the location of the reinforcement was determined according to scaling rule. Location of the reinforcement deserves further discussion.

\section{A.2. Distortion Due to the Reinforcement Location}

A close look at the scaled-up cross section reveals a distortion in the reinforcement locations. For practical reasons, the centroid of the longitudinal bars is located nominally at $15 \mathrm{~mm}$ from the face of the concrete in the test structure. Upon conversion to the prototype scale, this value corresponds to $75 \mathrm{~mm}$, which is not typical in practice. This distortion can have effects on the moment and stiffness values.

To see the effect of the reinforcement location, the moment capacity of the prototype section is also calculated by positioning the longitudinal reinforcement at $45 \mathrm{~mm}$ from the face of the concrete. Comparing the results shows that the test structure section has a $15 \%$ less capacity than it should have after scaling.

A similar study on the cracked flexural stiffness shows that the stiffness of the model is approximately $25 \%$ less than the prototype after scaling.

\section{A.3. Rotation at the Plastic Hinges}

Considering the slenderness of the frame members, rotation of the plastic hinges can be decomposed into two main components: (a) the curvature at the yielding portion of the member and (b) the slip of the bar.

Calculating the moment curvature relations shows that, similar to the moment capacity, as long as the longitudinal reinforcement is kept at its location according to the scaling, the moment and curvature values obey the scaling rule. On the other hand, if the longitudinal bars move to $45 \mathrm{~mm}$ from the surface, the yield curvature of the test structure increases by $18 \%$ and the maximum curvature decreases by $20 \%$ compared to the prototype.

The effect of the scaling of the slip of the bars can be discussed simply on the bar development length formulation:

$$
\begin{array}{r}
l=\frac{\sigma_{s} \cdot A_{b}}{u \cdot P_{b}}, \text { where } \sigma_{s}: \text { stress in the reinforcement } \\
\mathrm{A}_{\mathrm{b}}: \text { area of the reinforcement } \\
\mathrm{u}: \text { allowable bond stress } \\
\mathrm{P}_{\mathrm{b}}: \text { perimeter of the bar }
\end{array}
$$


The slip of the bar can be calculated by integrating the assumed strain distribution on the development length. Because the strain is free from the effect of scaling, it can be concluded that the slip of the reinforcement obeys the scaling rule with a length scale of $1 / 5$.

Total rotation of the plastic hinge can be roughly divided equally between the contributions of the curvature and the slip of the bar. Therefore, considering the distortion of the bar location, the plastic rotation in the test structure can be estimated as $10 \%$ more at the yield and $10 \%$ less at the ultimate than that of a prototype.

\section{A.4. Discussion on the Effect of the Scaling on the Parameters of the Study}

In the preceding paragraphs, it was demonstrated that scaled parameters can be directly extrapolated to a prototype with some exceptions. The practical locations of the longitudinal bars in a prototype structure are not fully compatible with the test structure. The moment capacity, flexural stiffness, and plastic rotations at the member ends are subjected to distortions. The magnitudes of these distortions are approximately $15 \%$ for the moment capacity, $25 \%$ for the flexural stiffness, and $10 \%$ for the plastic rotation values.

The flexural stiffness and the plastic rotation values have direct effects on the deformation of the frames. The flexural stiffness is effective on the deformation until the members start to form plastic hinges. Therefore, at low intensity loading, the results of the test structure have relatively larger offsets. On the other hand, at large intensity loading, the plastic hinges are more effective on the drift and the test structure have an offset of approximately $10 \%$. Because the study presented here is specifically interested with the condition of frames at extreme conditions, the offset in the deformation due to the location of the reinforcement is approximately $10 \%$, which is within acceptable bounds.

The deviation in the moment capacity can have implications on the lateral force level and hysteresis relations. Depending on the lower moment capacities on the test structure sections, lateral force levels can be approximately $15 \%$ lower than those of the prototype. The hysteresis curves can be affected by both the decrease in the drift and the lateral load. Because both the lateral load and the drift are approximately 10-15\% lower, the shape of the hysteresis curve will not be affected. On the other hand, hysteresis energy will be approximately $20 \%$ less than that of a prototype after scaling.

Even if the similitude laws are satisfied in the scaled experiment, the additional variations due to the size effects are unavoidable. The main reason for such effects is the higher probability of defects in a full size test. For the presented study, the strength and stiffness of the infill walls can be affected by the size effects. Hence, the strength and stiffness values tend to be higher compared to those of the full size walls. It can be concluded that the deviations in the strength and the stiffness that are caused by the improper location of the bars in the model and the size effects are working against each other. The final distortions should be expected to be smaller than stated in the preceding paragraphs.

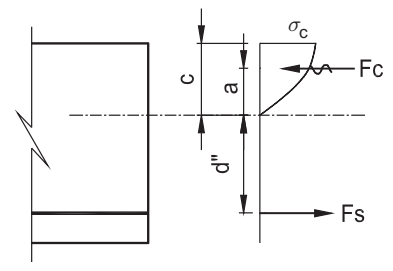

$$
\begin{aligned}
& \text { Note that } a=\frac{5}{8} c \\
& \text { Volume of the compression zone }=\frac{2}{3} \sigma_{c} \cdot c
\end{aligned}
$$

FIGURE A1 Force couple for a member in flexure. 
TABLE A1 Corresponding ratios of internal forces and moment arm

\begin{tabular}{llll}
\hline & Model & $\begin{array}{c}\text { Corresponding } \\
\text { Prototype }\end{array}$ & \multicolumn{1}{c}{ Model to Prototype Ratio } \\
\hline Tension Force & $f_{y} \cdot A_{s_{\_} m}$ & $f_{y} \cdot A_{s_{-} p}$ & $\frac{A_{s_{\_} m}}{A_{s_{-} p}}=\frac{1}{25}$ \\
Compression Force & $\sigma_{c} \cdot A_{\text {parabola_m }}$ & $\sigma_{c} \cdot A_{\text {parabola_p }}$ & $\frac{A_{\text {parabola_m }}}{A_{\text {parabola_p }}}=\frac{\frac{5}{8} c_{m} \cdot b_{w}}{\frac{5}{8} c_{p} \cdot b_{p}}=\frac{1}{25}$ \\
& & & $\frac{d_{m}^{\prime \prime}+a_{m}}{d_{p}^{\prime \prime}+a_{p}}=\frac{1}{5}$ \\
\hline
\end{tabular}

\section{Appendix B: Limit Analysis}

A preliminary analysis of the failure mechanisms revealed that the $1^{\text {st }}$ story mechanism is governing the failure of the model frames under a given load distribution. Referring to figure below, the failure load is calculated as:

$$
\begin{array}{ll}
\text { Failure Load: } & F_{L}=(4 K+3 K+2 K+K)=10 K \\
\text { External work: } & W_{E}=(4 K+3 K+2 K+K) \cdot\left(\alpha \cdot h^{\prime}\right) \\
\text { Internal work: } & W_{I}=\left(M_{l_{-} b o t}+M_{l_{-} \text {top }}+M_{r_{-} b o t}+M_{r_{-} \text {top }}\right) \cdot \alpha \\
& \text { OR } \quad W_{I}=M_{\text {first_story }} \cdot \alpha,
\end{array}
$$

where $M_{l_{-} b o t}, M_{l_{-} t o p}, M_{r_{-} b o t}$, and $M_{r_{-} t o p}$ are the moments at the top and bottom ends of the left and right columns.

Therefore, based on the equilibrium of the internal work to the external work, the failure load is calculated as

$$
F_{L}=\frac{M_{\text {first_story }}}{h^{\prime}}
$$

To estimate the ultimate lateral force resisted by the frames, the moment capacities of the first story columns were calculated using the measured material strengths and the reinforcement layout. Because the physical size and location of the plastic hinges could not be obtained explicitly, and this is a matter of debate among researchers, three alternative plastic hinge axis locations were considered to determine $h^{\prime}$ : (1) the hinge axis is at the column-beam interface; (2) the hinge axis is at a distance of h/2 (see Fig. B1b) from the face of the column; and (3) hinge axis is at a distance $\mathrm{h}$ from the face of the column. The results obtained are listed in the table below.

The lateral load capacities reached by Frames \#1 and \#2 during the tests are $20.3 \mathrm{kN}$ and $19.7 \mathrm{kN}$, respectively. Within the context of the test parameters, it can be concluded that a limit analysis with a plastic hinge axis at a distance of about $\mathrm{h} / 2$ to $\mathrm{h}$ from the beam column interface gives matching results with the measured values. The estimated successful plastic hinge axes are in the proximity of the accepted locations.

A limit analysis requires the ultimate moment capacities of the sections and the dimensions of the frame for the calculation of the failure capacity. As was demonstrated, the 

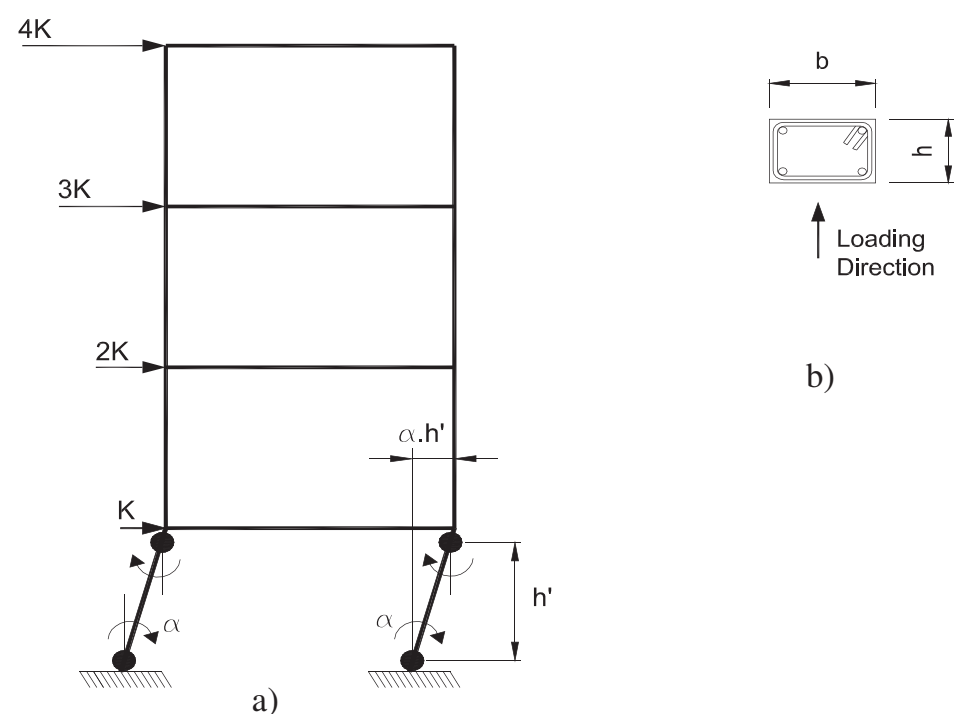

b)

FIGURE B1 (a) The first story failure mechanism; and (b) the cross section of a column.

TABLE B1 The lateral strength of the frames obtained from limit analysis

\begin{tabular}{lcc}
\hline Frame/Location of the plastic hinge & Frame \#1 $(\mathrm{kN})$ & Frame \#2 $(\mathrm{kN})$ \\
\hline Case (1) & 18.2 & 17.2 \\
Case (2) & 19.5 & 18.4 \\
Case (3) & 21.0 & 19.8 \\
\hline
\end{tabular}

moment capacity of a RC section obeys a linear scaling as long as the longitudinal reinforcement axis is kept in order with the scaling. However, such an attempt causes a thick, impractical concrete cover on the reinforcement. Moving the reinforcement into practical locations results in lower moment capacities in the test structure compared to those in the prototype. The moment capacities for the test structure are calculated to be $15 \%$ lower than those of a prototype structure. 